\title{
Mycobiome Composition and Diversity under the Long-Term Application of Spent Mushroom Substrate and Chicken Manure
}

\author{
Magdalena Frąc *DiD, Giorgia Pertile D , Jacek Panek (D), Agata Gryta, Karolina Oszust, Jerzy Lipiec \\ and Bogusław Usowicz (D)
}

Citation: Frąc, M.; Pertile, G.; Panek, J.; Gryta, A.; Oszust, K.; Lipiec, J.; Usowicz, B. Mycobiome Composition and Diversity under the Long-Term Application of Spent Mushroom Substrate and Chicken Manure. Agronomy 2021, 11, 410. https:// doi.org/10.3390/agronomy11030410

Academic Editors:

Małgorzata Szczepanek,

Anna Piotrowska-Długosz and

Iwona Konopka

Received: 31 January 2021

Accepted: 21 February 2021

Published: 24 February 2021

Publisher's Note: MDPI stays neutral with regard to jurisdictional claims in published maps and institutional affiliations.

Copyright: (c) 2021 by the authors. Licensee MDPI, Basel, Switzerland. This article is an open access article distributed under the terms and conditions of the Creative Commons Attribution (CC BY) license (https:// creativecommons.org/licenses/by/ $4.0 /)$
Institute of Agrophysics, Polish Academy of Sciences, Doświadczalna 4, 20-290 Lublin, Poland; g.pertile@ipan.lublin.pl (G.P.); j.panek@ipan.lublin.pl (J.P.); a.gryta@ipan.lublin.pl (A.G.); k.oszust@ipan.lublin.pl (K.O.); j.lipiec@ipan.lublin.pl (J.L.); b.usowicz@ipan.lublin.pl (B.U.)

* Correspondence: m.frac@ipan.lublin.pl; Tel.: +48-81-7445061; Fax: +48-81-7445067

\begin{abstract}
Waste exogenous organic matter, including spent mushroom substrate (SMS) and chicken manure (CM), can be used as the basis of a soil-improving cropping system in sustainable agriculture. However, there is-as yet-a lack of information about important quality indicators such as the fungal community relative abundance, structure and biodiversity in soils treated with these additives. In this study, the responses of the soil fungal community composition and mycobiome diversity to SMS and CM application compared to the control soil were evaluated using a combination of the following molecular approaches: quantitative polymerase chain reactions, denaturing gradient gel electrophoresis, terminal restriction fragment length polymorphism, and next-generation sequencing. The most abundant phylum for both treatments was Ascomycota, followed by Basidiomycota. The application of SMS and CM increased the abundance of fungi, including Tremellomycetes and Pezizomycetes for the SMS additive, while the Mortierellomycetes, Pezizomycetes, and Leotiomycetes levels increased after CM addition. SMS and CM beneficially reduced the relative abundance of several operational taxonomic units (OTUs) which are potential crop pathogens. The results provide a novel insight into the fungal community associated with organic additives, which should be beneficial in the task of managing the soil mycobiome as well as crop protection and productivity.
\end{abstract}

Keywords: fungal fingerprinting; microbiome; mycobiota; phytopathogens; exogenous organic additives; soil fungal diversity

\section{Introduction}

The addition of exogenous organic matter to soil is important, because it has a significant influence on the chemical, physical and biological properties of the soil, and because it plays a role in carbon sequestration. Fungi play a significant role in the decomposition of organic additives in the soil environment [1,2].

Spent mushroom substrate (SMS) is a recycled composted organic material that remains after harvesting a mushroom crop. In general, SMS consists of agricultural residues with the addition of poultry manure, coal, peat and other substances. High amounts of SMS are generated during mushroom production, especially in China, Italy, the USA, the Netherlands, Poland, Spain and France. For every $1 \mathrm{~kg}$ of mushrooms produced, $5 \mathrm{~kg}$ of SMS are generated [3]. The physicochemical properties of SMS vary with its composition. It has a $\mathrm{pH}$ in the range of 6.13-6.70 and also has a higher content of nitrogen, phosphorus, calcium and magnesium than manure [4]. The porosity and water-holding capacity of SMS vary between 14.50 and $26.20 \%$, and 28.00 and $41.00 \%$, respectively [5]. SMS is also characterized by a high content of organic matter and a low toxic element content $[4,6]$. Therefore, in recent years, spent mushroom substrate has been investigated in various research studies as a soil additive $[7,8]$. To date, the reported beneficial effects of the application of SMS to soil include improving the soil structure, managing plant diseases, and the biodegradation and biosorption of organic contaminants [3,9]. The application of 
SMS to soil has positive effects on microbial activity, the organic matter content and soil fertility [10].

Chicken manure (CM) is a rich organic fertilizer containing significant amounts of nitrogen due to the presence of high levels of protein and amino acids. Moreover, it contains all of the essential nutrients $(\mathrm{P}, \mathrm{K}, \mathrm{Mg}, \mathrm{Ca}, \mathrm{S})$ that support crop production and enhance the physical and chemical properties of the soil [11]. The application of chicken manure improves soil water retention and the uptake of plant nutrients. In addition, the application of chicken manure can influence the soil's microorganism abundance, structure, and activity [12]. However, the regular use of this organic additive may cause soil fungal community shifts which can influence plant growth and soil health [13-15].

We hypothesized that fungal communities would be strongly influenced by exogenous organic matter-such as spent mushroom substrate and chicken manure-and that the abundance and richness of the mycobiota would increase, whereas the pathogen content would decrease after SMS and CM addition into the soil.

The aim of this study was to determine the effects of the long-term application of spent mushroom substrate and chicken manure on the relative abundance and fingerprinting patterns of the fungal community in the soil, in order to assess the usefulness of these exogenous organic materials in sustainable crop production. We applied a combined methodological approach using quantitative PCR (qPCR), denaturing gradient gel electrophoresis (DGGE), terminal restriction fragment length polymorphism (t-RFLP), and next generation sequencing (NGS) through Illumina MiSeq technology in order to determine the soil fungal composition and diversity for each type of applied organic additive, and to understand the holistic long-term effect of SMS and CM on soil mycobiota. Comprehensive molecular analyses with the different methods can give more insight into the fungal relationship in soil environment after exogenous organic matter amendments, including the fungal abundance, structure, biodiversity and composition of the fungal community. The DGGE and t-RFLP are 'old school', reliable techniques for microbial community screening to describe ecological diversity, and are related to about a $1 \%$ cut-off, reflecting the interactions of the dominant microorganisms among themselves and with their environment [16]. Moreover, in order to identify the dominant fungi, TRiFLe analysis [17] was performed based on the size of the most abundant T-RF fragments. High-throughput gene amplicon sequencing techniques also provide a more in-depth microbial community profile $[18,19]$. Therefore, we decided to combine these approaches and assays in this study; to the best of our knowledge, the fungal responses to the long-term application of SMS and CM additives have not been investigated before.

\section{Materials and Methods}

\subsection{Site Description and Soil Sample Collection}

The experimental site was located in Trzebieszów, in the Podlasie Region of Poland. The region consists mainly of Podzol soils [20] of glacial origin, which are considered to be low-productivity soils. They contain $86 \%$ sand, $12 \%$ silt, and $2 \%$ clay, and they are acidic ( $\mathrm{pH}$ 3.9-5.0). The weather conditions have a mean annual temperature of $7.1^{\circ} \mathrm{C}$, and an annual precipitation of $550 \mathrm{~mm}$. The altitude of the study site is about $150 \mathrm{~m}$.a.s.l. The Trzebieszów commune is of a typical agricultural character, with about $62 \%$ arable land, $18 \%$ meadows and pastures, and $14 \%$ forests [21].

The treatments of the study are as follows: SMS - the soil was enriched with the spent mushroom substrate $\left(20 \mathrm{t} \mathrm{ha}^{-1}\right)$ (N 51.994215; E 22.55112); CM-chicken manure-enriched soil (10 tha ${ }^{-1}$ ) (N 51.990203; E 22.59253); and CS—control soil with mineral fertilization (N 51.99773; E 22.54812) from a completely randomized field experiment with plots areas of $10 \mathrm{~m}^{2}$. SMS and CM were applied over 20 years, and the crop rotation during this time included rape-wheat-maize-triticale. Although we were not focused on potentially harmful trace elements like arsenic, copper and zinc in the present study, based on the previous study $[4,22]$ and information collected from farmers who used these materials, it can be confirmed that the content of heavy metals in SMS and CM is very low, and is included 
in the range allowing this waste material to fertilizer. Moreover, in order to prevent pest growth and development in the SMS, this type of organic matter consisted of composted chicken manure and lime.

In total, 60 soil samples were collected from each treatment. The soil samples were collected as 3 subplots from each field using random composite sampling. For each subplot, the soil samples were collected randomly, avoiding untypical soil areas from 20 sites in order to obtain representative soil samples for each field. The fields were far apart from each other, from $0.4 \mathrm{~km}$ to $2.9 \mathrm{~km}$, as presented on a map (Figure S1).

The experimental site was described in the monograph under the redaction of Usowicz et al. [21]. The soil samples from the fields under cereal cultivation were collected on 29th June 2016 from 20 points for each subplot $(\sim 1 \mathrm{~kg})$ at a depth of $0-20 \mathrm{~cm}$, placed on ice, and transported to the laboratory. The soil samples for the molecular analyses were stored at $-20{ }^{\circ} \mathrm{C}$ until the tests were performed. Each soil sample was mixed in order to homogenize it, before being passed through a $2-\mathrm{mm}$ sieve and analysed. The air-dried and frozen soils were used for the chemical and microbial analyses, respectively.

\subsection{Analysis of the Soil's Chemical Properties}

The levels of the total concentration of phosphorus, potassium and magnesium were determined according to the Polish Standards [23-25]. The soil pH was measured potentiometrically. The total organic carbon (TOC) was assessed via the Tiurin method, and the total nitrogen by was measured by the Kjeldahl method [26]. These parameters were determined by the District Chemical and Agricultural Station (Lublin, Poland) according to the standard procedures. Soil water content was determined by weight method using moisture analyzer (Radwag, Radom, Poland). Analyses were performed as triplicates.

\subsection{Extraction of the Total Genomic DNA from the Soil Samples}

The total genomic DNA was extracted from nine soil samples, three for each fertilization treatment, using a previously described procedure [27]. In brief, $0.5 \mathrm{~g}$ soil was mixed with a solution from a FastDNA ${ }^{\circledR}$ SPIN Kit for Faeces (MP Biomedicals, USA), and the DNA was extracted according to the manufacturer's protocol. The amount of DNA was determined spectrophotometrically using a NanoDrop (Thermo Scientific, USA) at a wavelength of $260 \mathrm{~nm}$. The efficiency of the DNA extraction and its quality were evaluated through ratios of OD reads at 260/280 and 260/230 nm.

\subsection{Analysis of the Fungal Abundance by qPCR}

The fungal DNA was amplified by the use of the primers for the region ITS2, with an expected amplicon length $330 \mathrm{bp}$ with the primer sequences presented below. The quantification of the total fungal DNA was determined using an external standard curve composed of eight serially-diluted points from $10^{\wedge} 7$ to $10^{\wedge}-2$. It was generated from the serial dilution of the whole ITS fragment of fungal DNA obtained from Petriella setifera, Byssochlamys fulva, Neosartorya fischeri, Talaromyces ruber, Fusarium oxysporum, and Botrytis cinerea. The fungal DNA was extracted using the Plant \& Fungi DNA Purification kit (EURx, Poland). The amplification plot and the melting curve of the standard and negative template control obtained from the quantification of the fungal abundance are included in the Supplementary Materials as Figure S2. The PCR mixture contained a 0.5X Taq PCR Master mix (2X) $\left(50 \mathrm{mM}\right.$ Tris- $\mathrm{HCl} \mathrm{pH} 9$ at $25^{\circ} \mathrm{C}, 50 \mathrm{mM} \mathrm{NaCl}, 5 \mathrm{mM} \mathrm{MgCl}, 200 \mu \mathrm{M}$ each dNTP, $10 \mu \mathrm{g}$ activated calf thymus DNA, and $0.1 \mathrm{mg} / \mathrm{mL}$ BSA) (EURx, PL), 0.5X SG qPCR Master mix (2X) (EURx, PL), $0.2 \mu \mathrm{M}$ primer ITS3 and ITS4 (5'- GCA TCG ATG AAG AAC GCA GC $-3^{\prime}$, Tm $-53.8^{\circ} \mathrm{C}$ and $5^{\prime}$ - TCC TCC GCT TAT TGA TAT GC $-3^{\prime}$, Tm $49.7^{\circ} \mathrm{C}$ ) [28], $0.2 \mu \mathrm{g} / \mu \mathrm{l}$ Bovine Serum Albumin (Thermo Fisher Scientific, USA) and $2 \mu \mathrm{L}$ $0.1 \mathrm{ng} / \mu \mathrm{L}$ extracted DNA. The amplification of the fungal ITS2 regions was performed with the following amplification cycle: $95{ }^{\circ} \mathrm{C}$ for $5 \mathrm{~min}$, followed by 35 cycles at $95{ }^{\circ} \mathrm{C}$ for $15 \mathrm{~s}, 55^{\circ} \mathrm{C}$ for $30 \mathrm{~s}, 76^{\circ} \mathrm{C}$ for $30 \mathrm{~s}$, and $80{ }^{\circ} \mathrm{C}$ for $30 \mathrm{~s}$ (in this step, the machine made the data collection). All of the reactions were performed in quadruple replications in 
optical-grade 96-well plates on an ABI Prism 7500 Fast Real-Time PCR system (Applied Biosystems). The instrument automatically calculated the cycle threshold (CT), efficiency $\%(E \%)$, and $\mathrm{R}^{2}$. The $\mathrm{qPCR}$ validation was evaluated using agarose gel electrophoresis, a melting curve analysis, and qPCR efficiency. The fungal abundance consisted of four technical replications for each sample. The copies of the fungal ITS2 were calculated per the dry weight of the soil.

\subsection{Analysis of the Fungal Community Using the DGGE Approach}

The variations in the soil's fungal diversity were determined by the amplification of the region ITS1 through a nested PCR. In fact, at the first stage of the reaction, the whole region of ITS (ITS1 + 5.8S + ITS2) was amplified by using ITS1/ITS4 primers, but then in nested PCR only was the ITS1 fragment amplified with CG-ITS1/ITS2 primers [28]. 2.5. Analysis of the Fungal Community Using the DGGE Approach. All of the reactions were executed in a Veriti ${ }^{\circledR}$ 96-well Fast Thermal Cycler (Applied Biosystems, Foster City, CA, USA) in a $20 \mu \mathrm{L}$ reaction mixture. Each reaction on the first PCR contained: 1 X REDTaq ${ }^{\circledR} \operatorname{ReadyMix}^{\mathrm{TM}}$ PCR Reaction Mix (20 mM Tris- $\mathrm{HCl}$ pH 8.3 with $100 \mathrm{mM} \mathrm{KCl}, 3 \mathrm{mM} \mathrm{MgCl} 2,0.002 \%$ gelatin, $0.4 \mathrm{mM}$ dNTP mix and $0.06 \mathrm{unit} / \mu \mathrm{L}$ of Taq DNA Polymerase) (Sigma-Aldrich, USA), $0.2 \mu \mathrm{M}$ of both the primers ITS1 (5'- TCC GTA GGT GAA CCT GCG G $-3^{\prime}, \mathrm{Tm}-55.4{ }^{\circ} \mathrm{C}$ ) and ITS4 (5'- TCC TCC GCT TAT TGA TAT GC - $3^{\prime}$, Tm $\left.-49.7^{\circ} \mathrm{C}\right)$ [28], $0.2 \mu \mathrm{g} / \mu \mathrm{L}$ Bovine Serum Albumin (Thermo Fisher Scientific, USA) and $2 \mu \mathrm{L}$ of extracted DNA diluted 1:10 with the total amount of DNA $2 \mathrm{ng}$ in reaction. The thermocycling program for the Veriti ${ }^{\circledR}$ 96-well Fast Thermal Cycler (Applied Biosystems, Foster City, CA, USA) was performed in a similar way to a method which was reported by [29] with a modification in the extension step. The program consisted of an initial step of $3 \mathrm{~min}$ at $94^{\circ} \mathrm{C}$, followed by 35 cycles of denaturation at $94{ }^{\circ} \mathrm{C}$ for $1 \mathrm{~min}$, annealing at $55.5^{\circ} \mathrm{C}$ for $2 \mathrm{~min}$, and elongation at $72{ }^{\circ} \mathrm{C}$ for $2 \mathrm{~min}$. The last cycle was followed by an extension at $72^{\circ} \mathrm{C}$ for $30 \mathrm{~min}$. The size of the PCR products ranged from $\sim 500 \mathrm{bp}$ to $\sim 700 \mathrm{bp}$, due to the huge variability in the length of the ITS region for the fungi [30], which was visualized on a $2 \%$ agarose gel. The example of a gel picture from our study was presented on Figure S3 in the Supplementary Materials. Successively, $1 \mu$ l of the PCR-product was used for a nested PCR with primer CG-ITS1 (5' - CGC CCG CCG CGC GCG GCG GGC GGG GCG GGG GCA CGG GGG GTC CGT AGG TGA ACC TGC GG $-3^{\prime}$, Tm $\left.-88.9^{\circ} \mathrm{C}\right)$ and ITS2 $\left(5^{\prime}-\mathrm{GCT}\right.$ GCG TTC TTC ATC GAT GC $-3^{\prime}, \mathrm{Tm}-53.8^{\circ} \mathrm{C}$ ) [28]. The reaction mixture of the second PCR was the same as that of the first PCR, and the thermocycling program for the Veriti ${ }^{\circledR}$ 96-well Fast Thermal Cycler (Applied Biosystems, Foster City, CA, USA) was performed in a similar way to the method that was reported by [27], with the following modifications. The program consisted of an initial step of $5 \mathrm{~min}$ at $94^{\circ} \mathrm{C}$, followed by 35 cycles of denaturation at $94{ }^{\circ} \mathrm{C}$ for $1 \mathrm{~min}$, annealing at $56^{\circ} \mathrm{C}$ for $1 \mathrm{~min}$, and elongation at $72{ }^{\circ} \mathrm{C}$ for $1 \mathrm{~min}$. The last cycle was followed by an extension at $72{ }^{\circ} \mathrm{C}$ for $30 \mathrm{~min}$. The PCR products were visualized on $3 \%$ agarose gel. The ITS1 rDNA-DGGE was performed with $80 \mathrm{ng}$ DNA on $8 \%$ polyacrylamide gel with a $20-50 \%$ denaturing gradient. The electrophoretic run lasted for $16 \mathrm{~h}$ at $60 \mathrm{~V}$ and $60{ }^{\circ} \mathrm{C}$, using a TAE $1 X$ running buffer. Two replicates for each sample were analysed.

\subsection{Analysis of the Soil Fungal Community Using a t-RFLP Approach}

The whole ITS region was amplified to evaluate soil fungal diversity via t-RFLP analysis. The genomic DNA was amplified using a dilution of 1:10 of each sample analysed with a total amount of DNA in a reaction equal $2 \mathrm{ng}$. The reaction mixture included: $1 \mathrm{X}$ REDTaq ${ }^{\circledR}$ ReadyMix ${ }^{\mathrm{TM}}$ PCR Reaction Mix (20 mM Tris- $\mathrm{HCl}$ pH 8.3 with $100 \mathrm{mM} \mathrm{KCl,} 3 \mathrm{mM}$ $\mathrm{MgCl}_{2}, 0.002 \%$ gelatin, $0.4 \mathrm{mM} \mathrm{dNTP}$ mix and 0.06 unit/ $\mu \mathrm{L}$ of Taq DNA Polymerase) (Sigma-Aldrich, USA), $0.2 \mu \mathrm{M}$ of primer ITS1 with a $5^{\prime} \mathrm{FAM}$ fluorescent label (5'- 6-FAMTCC GTA GGT GAA CCT GCG G $-3^{\prime}$, Tm - $\left.55.4^{\circ} \mathrm{C}\right), 0.2 \mu \mathrm{M}$ primer ITS4 $\left(5^{\prime}\right.$ - TCC TCC GCT TAT TGA TAT GC $-3^{\prime}$, $\mathrm{Tm}-49.7^{\circ} \mathrm{C}$ ) [28], $0.2 \mu \mathrm{g} / \mu \mathrm{L}$ Bovine Serum Albumin (Thermo Fisher Scientific, USA), 2 ng extracted DNA and nuclease-free water to arrive at a total volume of $20 \mu \mathrm{L}$. The PCR condition was the same as that used in the first run for the 
DGGE analysis. The 500-700 size of the PCR-products were visualized on a $2 \%$ agarose gel. The PCR-product was digested separately with HaeIII (EURx, PL) and MseI (New England Biolabs, USA) restriction enzymes in a final volume of $30 \mu \mathrm{L}$ containing $20 \mu \mathrm{L}$ of the PCR-product, $1 X$ Buffer and $4 \mathrm{U}$ of restriction enzyme. The samples were incubated at $37^{\circ} \mathrm{C}$ for $2 \mathrm{~h}$ and this was followed by deactivation at $80^{\circ} \mathrm{C}$ for $20 \mathrm{~min}$ for the HaeIII enzyme and $65^{\circ} \mathrm{C}$ for $20 \mathrm{~min}$ for the MseI enzyme. After digestion, $1 \mu \mathrm{l}$ of each sample was mixed with $9 \mu \mathrm{L}$ of Hi-Di Formamide (Applied Biosystems, USA) and $0.5 \mu \mathrm{L}$ of GS-600 LIZ Standard (Applied Biosystems, USA). Before analysing the fragments, the samples were incubated at $95{ }^{\circ} \mathrm{C}$ for $3 \mathrm{~min}$ and at $4{ }^{\circ} \mathrm{C}$ for $3 \mathrm{~min}$. The fragment size analysis consisted of three technical replications for each sample and was carried out with an Applied Biosystems 3130 Genetic Analyser (Applied Biosystems, Foster City, CA, USA). The obtained results were analyzed using GeneMapper v. 4.0. software (Applied Biosystems, Foster City, CA, USA). The analysis included restriction fragments with a size range from $50 \mathrm{bp}$ to $660 \mathrm{bp}$ within the samples including peaks area higher than $1 \%$. Based on in silico analysis using TRiFLe software tool [17] the terminal restriction fragments (T-RFs) were identified using The National Center for Biotechnology Information (NCBI) database (https:/ / www.ncbi.nlm.nih.gov/, accessed on 19 February 2021) [31].

\subsection{Analysis of the Soil Fungal Community Composition Using Illumina MiSeq Platform Sequencing}

An analysis of the fungal community structure was performed based on the ITS1 region. The set of primers ITS1FI2/5.8S (5'- GAACCWGCGGARGGATCA - $3^{\prime} ; 5^{\prime}$ - CGCTGCGTTCTTCATCG -3') [32,33] was used to amplify the ITS1 region. The PCR amplification was carried out in a Q5 Hot Start High-Fidelity 2X Master Mix according to the conditions included in the manufacturers' protocols. The DNA library was sequenced using an Illumina MiSeq platform with pair-end (PE) technology, at 2x250 bp, using the v2 Illumina kit following the manufacturers' instructions. MiSeq Reporter (MSR) v2.6. software was used for a preliminary elaboration of the data, and the Quantitative Insights into Microbial Ecology (QIIME) tool was used to process the raw sequence reads [34]. First, the raw reads were analysed by Cutadapt (v. 1.9.1) in order to cut the remaining sequences of adaptors and primers. Subsequently, the filtering of the sequences was based on the read quality, with a threshold equal 20 (q20), which was used to trim low-quality ends from the reads before the adapter removal, and for read lengths with a threshold equal $30 \mathrm{bp}$ (m30), in order to discard the pair if one of the reads was too short. Then, the analysis included the following steps: read joining and quality evaluation via fastq-join [35], the removal of low quality sequences (quality filter at Phred $\geq$ Q20) and chimeras (usearch61), the generation of operational taxonomic units (OTUs), which were defined by clustering at $97 \%$ similarity. Then, low-abundance OTUs (minimal OTT size 10) were filtered out. The taxonomical classification of the OTUs was achieved using a Basic Local Alignment Search (BLAST) against the UNITE database. The next generation sequencing was performed in Genomed S.A. (Warsaw, Poland). Finally, the FUNGuild online application was used to assign functional information, including the trophic mode and ecological guild of the fungi [36], to the OTUs obtained in the high-throughput sequencing datasets.

\subsection{Statistical Analysis}

An analysis of variance (ANOVA) and a post-hoc test Tukey's HSD were used to determine the differences in the number of ITS2-copies (qPCR), Shannon, Simpson and Richness indices between the treatments, based on three replicates of soil for each treatment, as described in the section on sample collection (2.1.). Based on a cluster analysis, the dendrograms were prepared with a scaled similarity \% on the axis (Ward's method and the Unweighted Pair Group Method with Arithmetic Mean-UPGMA), and a boundary was marked according to Sneath's criteria. A heat map and a Venn diagram which show the relative abundances of the identified fungal sequences at species level $>1 \%$ in the sample were generated based on the OTUs (NGS) and $t$-RFs fragments (t-RFLP) via the online tool http:/ / bioinformatics.psb.ugent.be/webtools/Venn/(accessed on 19 February 2021). 
The fungal $\alpha$-diversity was assessed following Shannon and Simpson's diversity indices, and the richness of relative abundance. The analyses were performed using the following software: R v.3.2.5 and Statistica v.13.1.

\section{Results}

\subsection{Soil Properties}

The effects of the spent mushroom substrate (SMS) and chicken manure (CM) on the soil chemical properties are summarized in Table 1. Both additives increased the soil nutrient concentrations-including $\mathrm{N}, \mathrm{P}, \mathrm{K}$ and $\mathrm{Mg}$ - compared to the control soil (CS). The soil $\mathrm{pH}$ was 4.95 for the control; it increased to 7.08 and 6.68 after the addition of SMS and $\mathrm{CM}$, respectively. Furthermore, the total organic carbon content increased by about four and five times after the application of CM and SMS, respectively, compared to the control soil.

Table 1. Properties of soil under different treatments. Explanations: SMS—spent mushroom substrate, CM—chicken manure, CS—control soil, SWC—soil water content (moisture), TOC—-total organic carbon.

\begin{tabular}{cccccccc}
\hline Treatments & $\mathbf{p H}_{\mathrm{KCl}}$ & $\begin{array}{c}\text { SWC } \\
\mathbf{( \% )}\end{array}$ & $\begin{array}{c}\text { TOC } \\
\mathbf{( \% )}\end{array}$ & $\begin{array}{c}\mathbf{N} \\
(\mathbf{g} / \mathbf{k g})\end{array}$ & $\begin{array}{c}\mathbf{P} \\
(\mathbf{m g} / \mathbf{1 0 0} \mathbf{g})\end{array}$ & $\begin{array}{c}\mathbf{K} \\
\mathbf{( m g / 1 0 0} \mathbf{~ g})\end{array}$ & $\begin{array}{c}\mathbf{M g} \\
(\mathbf{m g} / \mathbf{1 0 0} \mathbf{g})\end{array}$ \\
\hline SMS & 7.08 & 11.43 & 2.73 & 2.69 & 50 & 30 & 13 \\
CM & 6.68 & 11.43 & 2.03 & 0.87 & 49 & 18 & 9 \\
CS & 4.95 & 1.38 & 0.50 & 0.59 & 24 & 4 \\
\hline
\end{tabular}

\subsection{Effect of Organic Fertilization Treatments on Soil Fungal Abundance}

The fungal abundance in all of the soils was determined using qPCR that targeted the ITS2 region of the ribosomal RNA gene. The abundance of the fungi varied from $8.59 \times 10^{7}$ to $3.75 \times 10^{8}$ the quantity of ITS2 per gram of dry soil across all of the samples (Figure 1). The soil fungal abundance significantly increased both in the SMS- and CM-treated soil by about $430 \%$ compared to the control soil. The efficiency, R2, and the slope of the standard curve were 104\%, 0.99, and -3.2, respectively. As was mentioned in Section 2.4, the melting curve is presented on Figure S2.

\subsection{Effect of the Organic Fertilization Treatments on the Soil Fungal Diversity}

The DGGE profile of the fungal community based on the ITS1 region is shown in Figure 2. The fungal DGGE profiles in all of the tested soils comprised 17 bands on average. The fungal community patterns differed between the treatments. The typical bands were detected for each treatment. For both tested replicates, four (1-4), two (6-7) and one (5) bands were specific for the SMS, CM and CS treatments, respectively. The rest of the visible bands were common for all of the tested treatments. The fungal DGGE profiles obtained from the chicken manure treatment did not differ significantly from those of the control soil. However, the relative intensities of the selected bands from the SMS-treated soil increased compared with those resulting from the CM and CS treatments.

The dendrogram of the soil fungal similarity obtained by the DGGE analysis showed the similarities and differences among the treatments (Figure 2). The clustering of the fungal communities, based on $66 \%$ of Sneath's similarity criterion, revealed the existence of two groups, indicating relatively large differences between the SMS and the other treatments. The similarity matrix (Table S1) confirmed the distance between the tested treatments. The similarities between the SMS and CM or CS were $36.53 \%$ and $36.90 \%$, respectively. However, the percentage of similarity between the CM and CS was $65.75 \%$. The similarity of the DGGE profiles based on the Dice similarity coefficients was consistently high (more than $86 \%$ ) among all of the tested pairs of profiles (Figure 2, Table S1). 


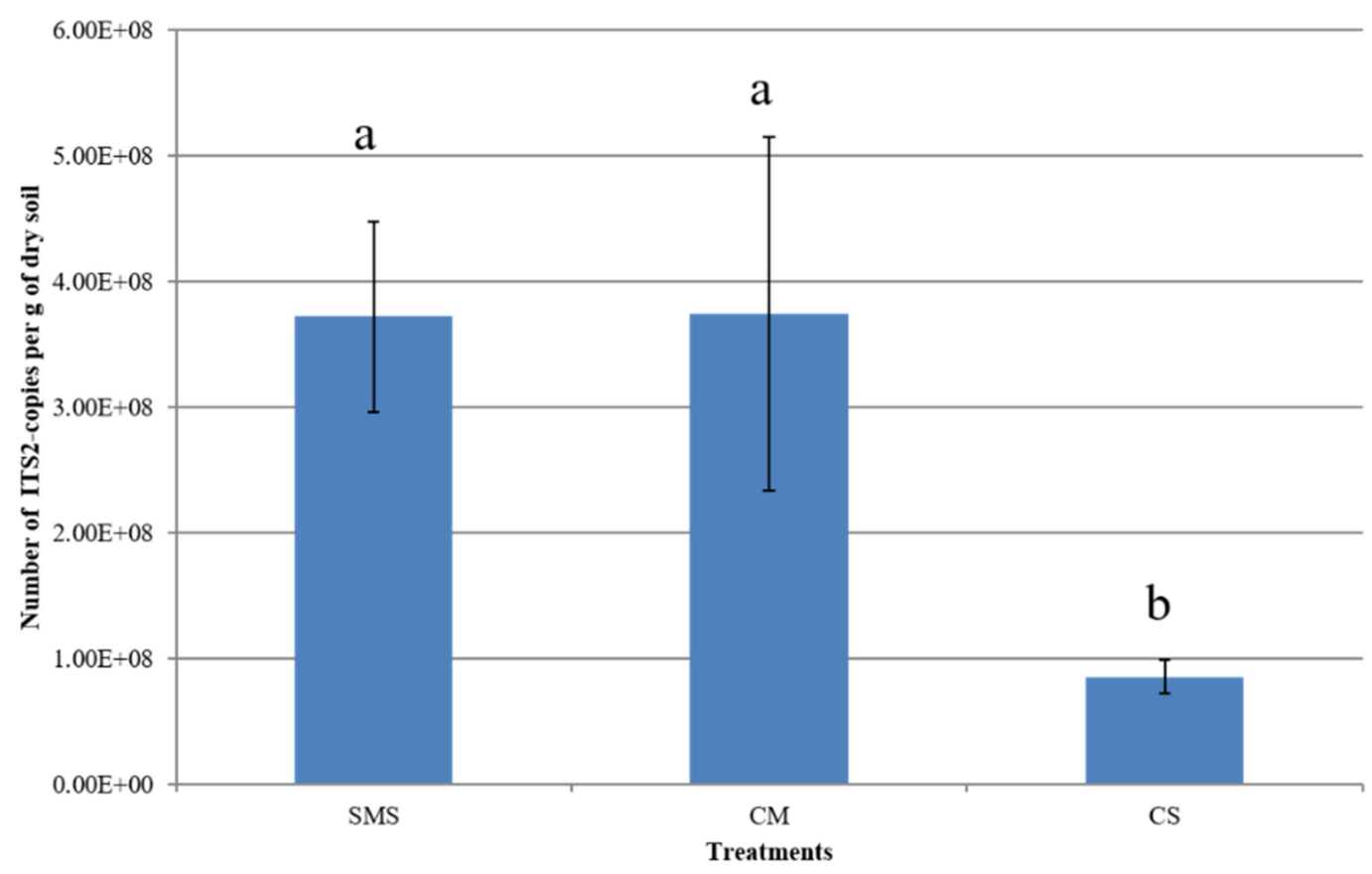

Figure 1. The abundance of fungi as indicated by the number of ITS2 copies as measured using quantitative PCR (qPCR). Different letters above columns denote a significant difference ( $p<0.05$, Tukey's test). SMS—spent mushroom substrate, $\mathrm{CM}$-chicken manure, CS—control soil; $n=12 ; 4$ replications for each treatment.

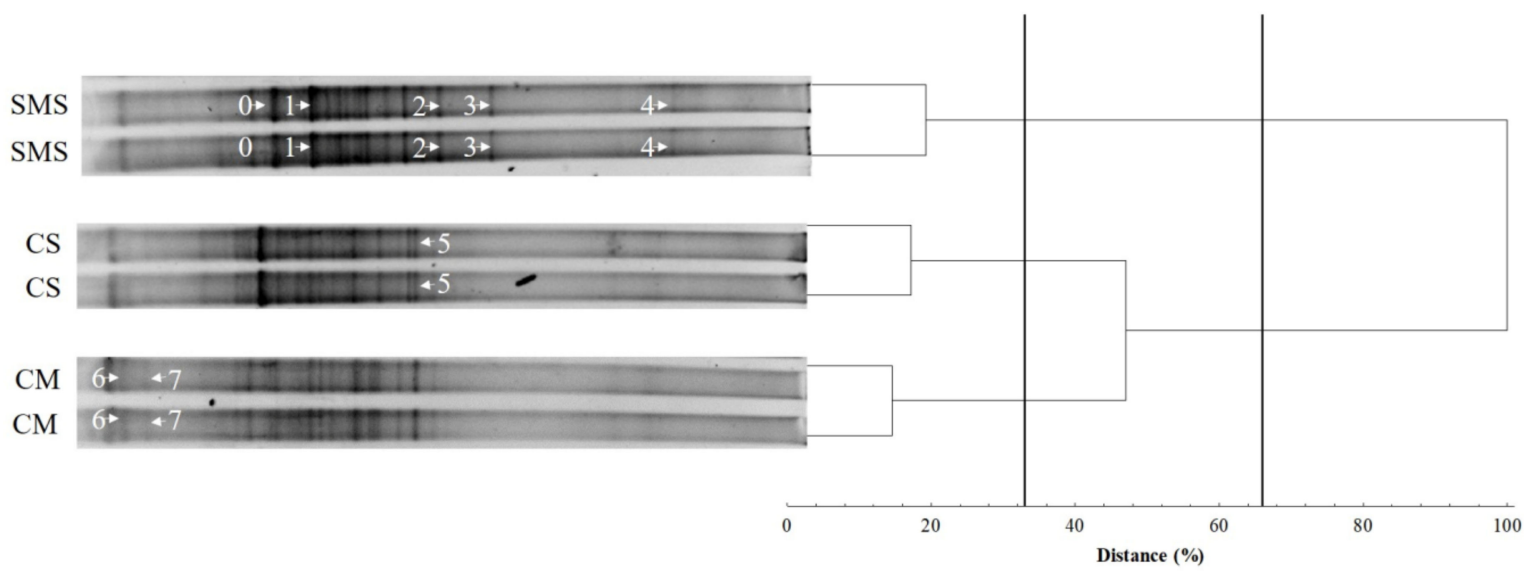

Figure 2. The DGGE profile of the fungal communities in soil treatments and the UPGMA dendrogram generated is based on the DGGE profiles. The numbers and arrows on the gel indicate specific bands related to the treatments. SMS-spent mushroom substrate, $\mathrm{CM}$-chicken manure, CS—control soil.

\subsection{The Fungal Community, as Determined by $t$-RFLP}

The t-RFLP approach, based on the whole ITS region, revealed especially significant changes in the fungal communities between the different tested soil treatments (Figures 3 and 4). Several peaks were detected from the fungal T-RFs that were within the range of the signal marker $(20-600 \mathrm{bp})$ used, that is, from 55 to $658 \mathrm{bp}$ (HaeIII) and 51-657 bp (MseI). The average T-RF richness, as derived from the number of peaks generated from the treatments tested, reached its highest level (31 - HaeIII, $27-$ MseI) using both restriction enzymes (Figure 3C). The lowest number of restriction fragments was found in the control soil (22 - HaeIII, 18 - MseI). However, following the SMS treatment, the richness of the T-RF was 25 and 21 for the HaeIII and MseI restriction enzymes, respectively. 
Vertical bars denote 0.95 confidence intervals
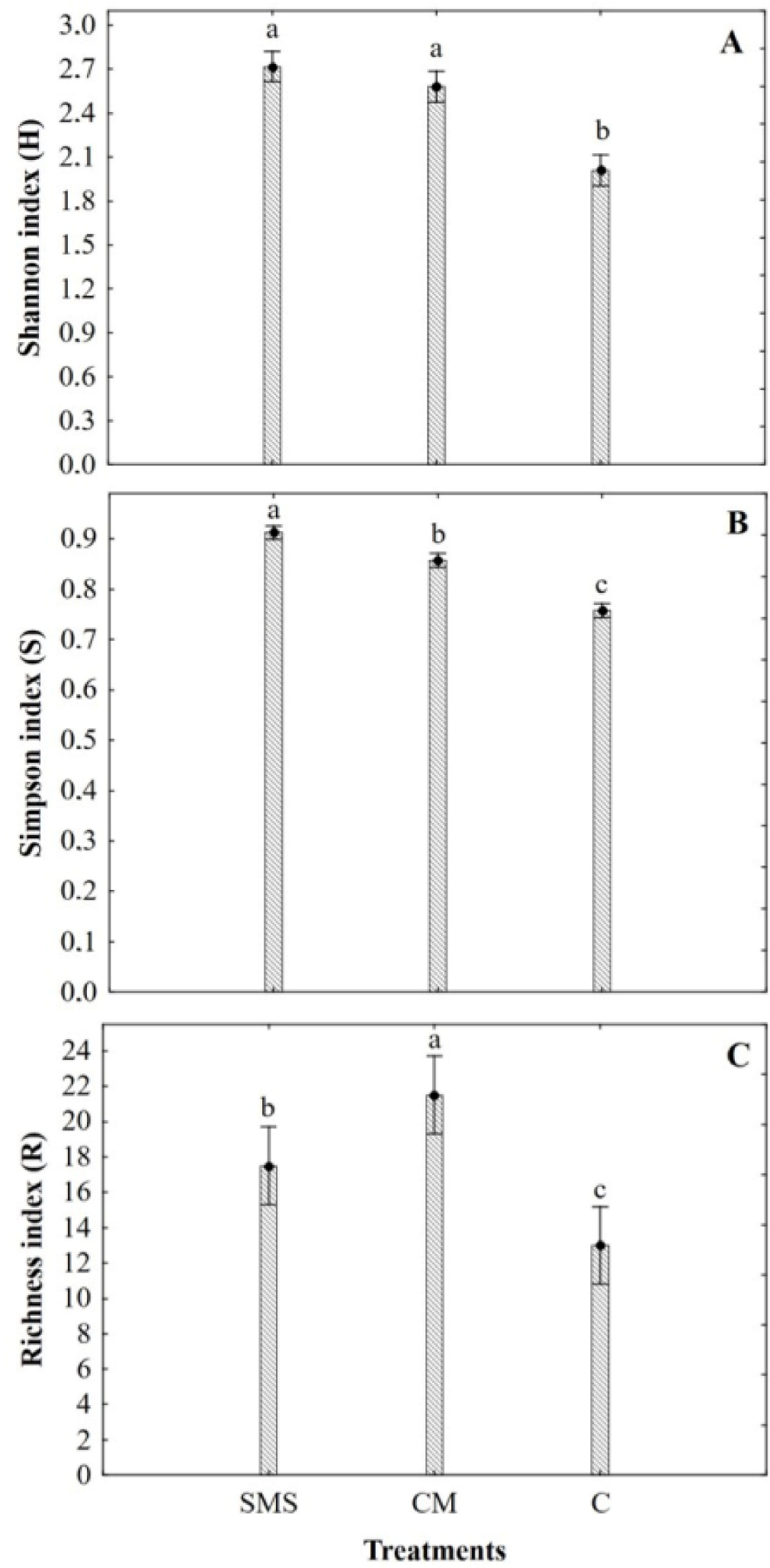

Figure 3. The diversity indices Shannon (A), Simpson (B) and Richness (C) are based on fungal ITS analysis by $\mathrm{t}$-RFLP calculated based on the average of both restriction enzymes. Different letters above columns denote a significant difference $(p<0.05$, Tukey's test). SMS—spent mushroom substrate, $\mathrm{CM}$-chicken manure, CS-control soil. 

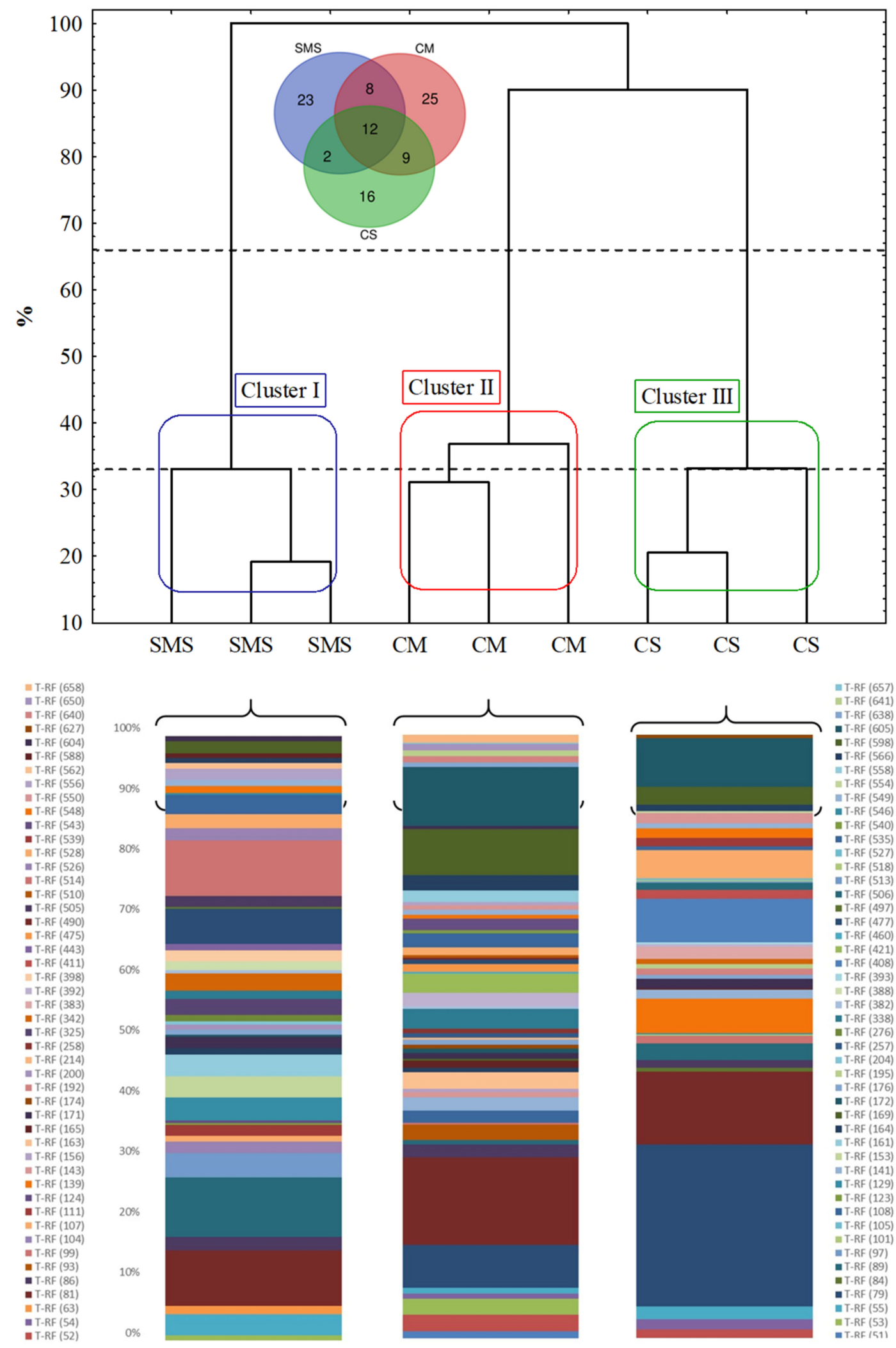

Figure 4. A dendrogram and Venn diagram based on the t-RFLP profiles of the fungal communities of ITS from all the treatments (above). The relative abundance of soil fungal t-RFs after the long-term organic amendment application (below). SMS—spent mushroom substrate, CM—chicken manure, CS—control soil. The cluster analysis was based on the Euclidean distances and Ward clustering method. 
The diversity indices, estimated by Shannon and Simpson's formulae, were significantly higher under SMS and CM compared to the control soil. The Shannon and Simpson's diversity indices reached their highest point following SMS treatment using both restriction enzymes (Figure 3A,B, Table S2).

The distribution in the abundance of various fragment sizes between the tested treatments is shown in Figure 4. The assessment of the abundance pattern of the fragment sizes in SMS and CM suggests that there is a tendency to increase the overall number of peaks and decrease their intensity compared to the control soil, with a lower number of peaks but with greater intensity, especially for the larger fragments. The t-RFLP diversity patterns obtained from all of the samples indicated the presence of more than 100 distinct T-RFs (Figure 4). Most of them were found in the CM (54) and SMS (45) treated soils, whereas $39 \mathrm{~T}$-RFs were detected in the control soil. In detail, as presented in the Venn diagram (Figure 3); 12 T-RFs of 55, 81, 86, 89, 171, 176, 528, 535, 548, 566 and 598 bp were present in all of the soil samples. Furthermore, 8 T-RFs of 53, 164, 172, 338, 382, 477, 556 and $604 \mathrm{bp}$ were detected in the SMS- and CM-treated soils, but not in the control soil. Finally, 16 T-RFs of 84, 101, 139, 192, 195, 383, 393, 411, 506, 513, 518, 527, 539, 554 and 627 were only observed in the control soil (Table S3). Based on the in silico analysis with the TRiFLe software tool [17], a predicted identification of fungi based on t-RFs fragment size was performed (Table S4). The predominant T-FRs 139 in the control soil could be represented by Metarhizium sp. (Table S4). The T-RFs 86, 548 and 566 present in all tested treatments (SMS, CM, CS) could be representatives of Trichoderma sp., Lophiostoma sp. and Derxomyces sp., respectively, while T-RF 89 could be represented by 13 different genera (Table S4) based on the in silico prediction analysis mentioned above.

A cluster analysis of the similarity values generated in this study was obtained using the UPGMA algorithm (Figure 4). The cluster diagram indicates that there is a very close grouping of the soil samples from each treatment (Cluster, I, II, III). In addition, analyzing Figures 2 and 4, we can observe that the CM and CS treatments were similar to each other in both types of analyses, DGGE and t-RFLP, while the SMS-treated soil was out of the cluster created by the CM and CS treatments, indicating the higher distance and diversity of the fungal community in this treatment. The cluster profile of the ITS fragments (ITS1 for DGGE and whole ITS for t-RFLP) obtained in both of the mentioned analyses demonstrated a clear separation between the fungal communities in the SMS-treated soil and those of the CM-treated soil and the control soil (Figures 2 and 4).

\subsection{Relative Abundance of the Fungi and Their Taxonomic Classification, as Determined by NGS}

The amount of raw Illumina sequences before the quality filtering was from 143,157 (CM) through 167,302 (CS) to 211,978 (SMS). In total, 393,102 high-quality ITS1 sequences were obtained from all of the samples. The sequences were classified as fungal ITS1 sequences by the UNITE databases, 60,377 to 140,400 sequences were obtained per treatment (Table 2; Table S5). The mean read length was $251 \mathrm{bp}$. When grouped at the $97 \%$ similarity at the genus level, there were 884 different phylotypes for all of the treatments, with 282, 283 and 319 phylotypes for SMS, CM and CS, respectively. The Illumina sequencing data were uploaded to the NCBI Sequence Read Archive database with accession number SRP130056. The number of sequences was normalized by the performance of rarefaction analyses. In order to obtain normalized sequences, the OTU table was subsampled by the pseudo-random number generator (an implementation of the Mersenne twister PRNG). Moreover, it is worth mentioning that the relative abundance, which is a fixed percentage composition, is independent of the number of reads.

The fungal sequences were classified into seven phyla across the entire data set. The following percentages of the dataset reads were assigned to particular taxonomic level Kingdom, Phylum, Class, Order, Family, Genus and Species: $100.00 \%, 97.98 \%, 74.74 \%$, $67.57 \%, 56.45 \%, 43.19 \%, 37.71 \%$ for SMS, $100.00 \%, 97.27 \%, 91.26 \%, 77.12 \%, 63.89 \%, 53.38 \%$, $34.69 \%$ for CM and $100.00 \%, 95.35 \%, 90.72 \%, 81.33 \%, 73.49 \%, 68.24 \%, 54.69 \%$ for CS, respectively (Table S5). The dominant fungal phyla across all of the soil samples were 
Ascomycota, Basidiomycota and Mortierellomycota, with the relative abundances of the OTUs ranging from $76.24 \%$ through $12.61 \%$ to $6.68 \%$ for SMS; from $71.33 \%$ through $9.14 \%$ to $15.35 \%$ for CM; and from $74.47 \%$ through $7.15 \%$ to $12.05 \%$ for CS (Figure 5). In addition, Chytridiomycota, Mucoromycota, Rozellomycota and Zoopagomycota were minor phyla, with the lower relative abundances being $0.32 \%, 0.26 \%, 0.13 \% ; 0.80 \%, 0.20 \%, 0.19 \% ; 0.58 \%$, $0.59,1.15 \%$ and $0.38 \%, 0.50 \%, 0.11 \%$ for the SMS, CM and CS treatments, respectively. The relative abundances of Glomeromycota were not detected in the SMS-amended soil, and were low in the other treatments, that is, $0.15 \%$ and $0.20 \%$ in CM-treated soil and CS, respectively. However, Blastocladiomycota were only present in the soil treated with SMS and CM at a low level of $0.08 \%$ and $0.25 \%$, respectively. The results showed that, in soil treated with spent mushroom substrate, the relative abundance of Ascomycota and Basidiomycota were higher than in the control soil, while Mortierellomycota were lower compared to the CS. However, in soil treated with chicken manure, the relative abundance of Ascomycota decreased, and Basidiomycota and Mortierellomycota increased compared to the control soil.

Table 2. Illumina MiSeq sequenced fungal data and fungal community $\alpha$-diversity indices based on the ITS1 gene at the genus level in soil amended with the spent mushroom substrate (SMS) and chicken manure (CM), and the control soil (CS). Explanations: OTUs, Operational Taxonomic Units. The observed OTUs, Shannon, and Simpson indices were calculated based on data normalized to an equal sequencing depth (at a reading depth of 60,000 ).

\begin{tabular}{cccccc}
\hline Treatments & $\begin{array}{c}\text { Number of OTUs } \\
\text { (Richness Index) }\end{array}$ & Shannon Index & Simpson Index & Total Number of Reds & Total Number of Genus \\
\hline SMS & 796 & 5.95 & 0.94 & 140400 & 241 \\
CM & 848 & 6.96 & 0.97 & 60377 & 245 \\
CS & 972 & 6.86 & 0.98 & 82296 & 276 \\
\hline
\end{tabular}

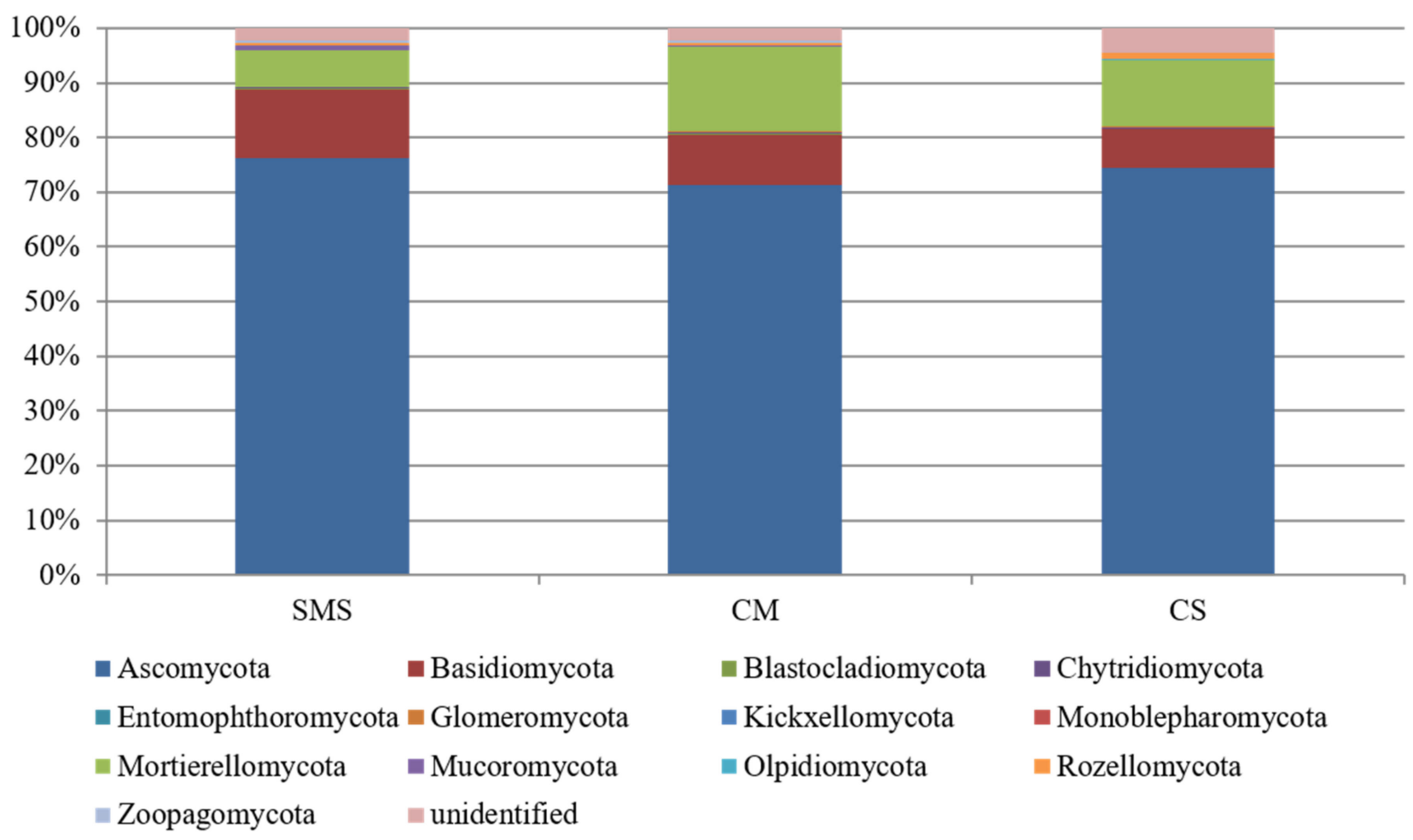

Figure 5. The relative abundance of the soil fungal phylum after the long-term organic treatment. SMS, spent mushroom substrate; $\mathrm{CM}$, chicken manure; CS, control soil. The fungal communities were examined through the next-generation sequencing (NGS) of the ITS1 region using Illumina MiSeq technology. 
The results indicated the evident differences among the treatments at the class level of taxonomic classifications (Figure 6). Based on the total high-quality sequences, Sordariomycetes, Tremellomycetes, Mortierellomycetes and Eurotiomycetes were the four dominant classes in all of the treatments, accounting for $34.35 \%, 10.78 \%, 6.68 \%$ and $9.88 \%$ for SMS-treated soil, $45.23 \%, 5.02 \%, 15.35 \%$ and $5.04 \%$ for CM-treated soil, and $46.94 \%$, $5.13 \%, 12.01 \%$ and $12.40 \%$ for the CS, respectively. Furthermore, four other classes of fungiLeotiomycetes, Pezizomycetes, Dothideomycetes, and Agaricomycetes, which accounted for an average of $4.42 \%, 4.40 \%, 2.43 \%$, and $1.89 \%$ of the total sequences, respectively-were detected in the present study. The remaining 30 classes that appeared along with the relatively abundant ones accounted for a relatively small proportion of the total amount of fungus; they ranged from $0.01 \%$ to $1.18 \%$. The addition of spent mushroom substrate increased the abundance of Tremellomycetes, Pezizomycetes and another unidentified Ascomycota, whereas it reduced the abundance of Sordariomycetes, Leotiomycetes, Dothideomycetes, Eurotiomyctes and Mortierellomycetes. However, increases in the relative abundance of Mortierellomycetes, Leotiomycetes and Pezizomycetes, and decreases in the levels of Sordariomycetes, Tremellomycetes and Eurotiomycetes were observed in the soil treated with chicken manure.

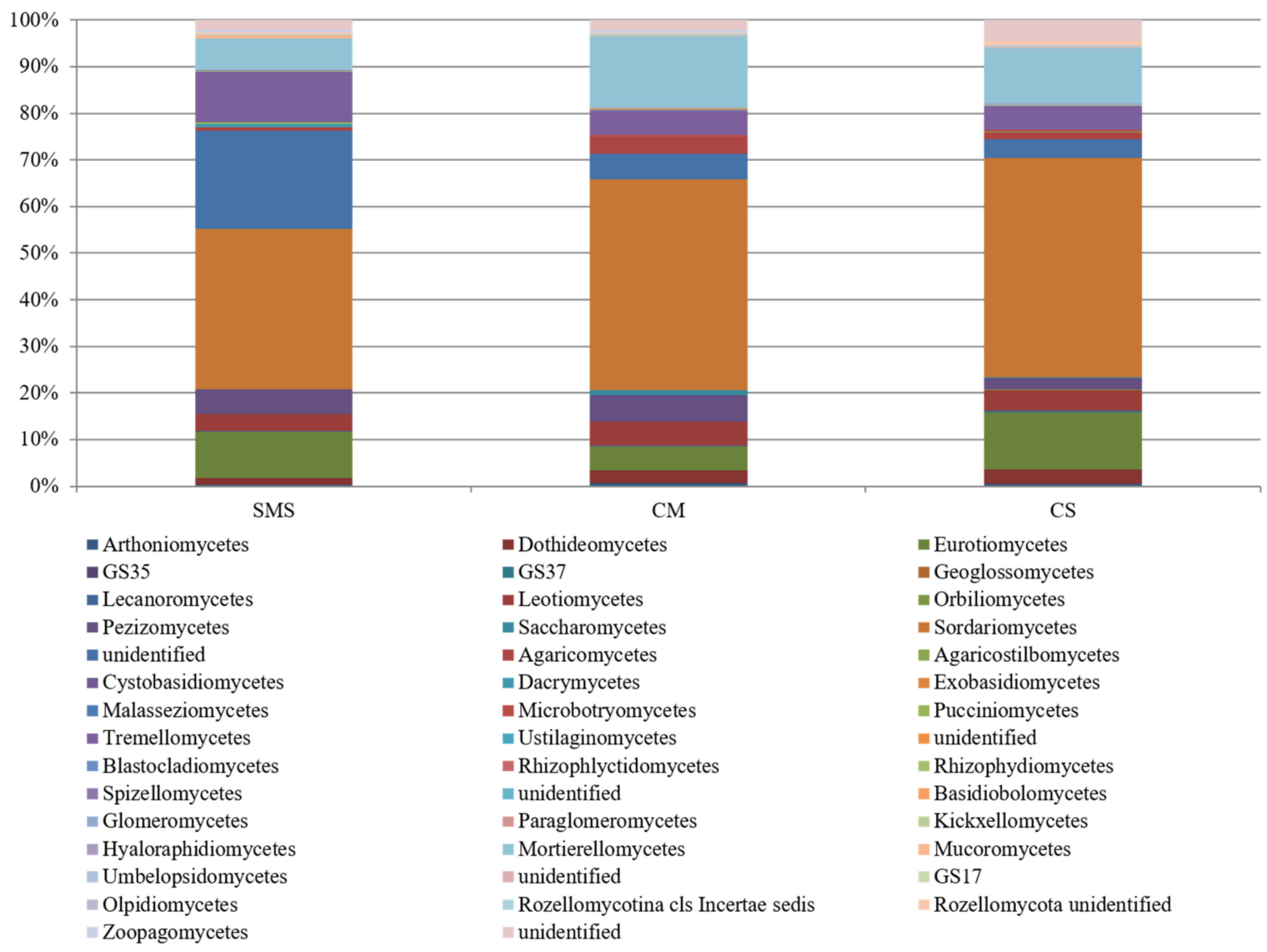

Figure 6. The relative abundance of the soil fungal class after the long-term organic treatment. SMS, spent mushroom substrate; CM, chicken manure; CS, control soil. The fungal communities were examined through the next-generation sequencing (NGS) of the ITS1 region using Illumina MiSeq technology.

Further taxonomical classification at the genus level revealed that 241-276 fungal genera were detected in this study, which indicated the differences in the fungal community among the tested treatments (Table S6). A thorough investigation of each genus selected according to their relative abundance $(\geq 1 \%)$ in each treatment is presented in Table 3 . The results showed that the fungal community in all of the treatments was dominated by 
Mortierella and Solicoccozyma. However, the sequence number of Mortierella was the highest for CM-treated soil (14.91\%); it was lower for CS soil (11.85\%), and the lowest for SMStreated soil $(6.52 \%)$. The relative abundance of Solicoccozyma in the SMS-treated soil $(4.50 \%)$ was greater than that of the CM-treated soil $(2.00 \%)$ and the CS $(2.90 \%)$. The percentage of Fusarium and Humicola was quite high, and was similar in all of the tested soils, with a level of $0.86 \%, 1.09 \%, 1.81 \%$ and $1.10 \%, 1.34 \%, 0.76 \%$ for the SMS-treated soil, CM-treated soil, and CS, respectively. The Cephalotrichum, Cutaneotrichosporon, Chrysosporium and Scutellinia for the SMS treated soil $(1.34 \%, 2.74 \%, 4.18 \%, 1.09 \%)$ surpassed that for CM treated soil $(0.09 \%,<0.01 \%, 1.22 \%, 0.58 \%)$ and CS $(0.12 \%, 0.05 \%, 2.26 \%, 0.04 \%)$. Ascobolus, Apodus, Cadophora, Candida, Cladorrhinum, Pseudaleuria, Plectosphaerella and Trichoderma were at their highest level for the CM-treated soil (1.99\%, 1.09\%, 2.24\%, 0.68\%, 1.54\%, 1.44\%, 1.00, $1.08 \%$ ), and Acremonium, Aspergillus, Exophiala, Metarhizium, Penicillium, Podospora and Pseudogymnoascus were at their highest for CS $(1.87 \%, 1.07 \%, 2.77 \%, 13.96 \%, 4.76 \%, 1.37 \%$, $3.02 \%$ ) (Table 3, Table S6).

In order to further illustrate the impact of exogenous organic matter on the composition of the fungal community, the most abundant of the detected species (with relative abundances greater than $1 \%$ of identified species) were compared between the treatments (Figure 7). However, approximately $50 \%$ of the fungal sequences across all of the samples were not classified into a definite species. Among all of the species detected in the SMStreated soil (418), CM-treated soil (418) and CS (475) soil samples (Table S6), 25, 25, and 20 identified species were dominant in the soils treated with the spent mushroom substrate, chicken manure, and the control, respectively (Figure 7). In general, the abundance of the fungal species was influenced by SMS or CM addition (Figure S4). The four species Cutaneotrichosporon moniliiforme, Solicoccozyma terrea, Chrysosporium pseudomerdarium and Pseudogymnoascus verrucosus were the most dominant in the soil treated with spent mushroom substrate, and their abundance was as follows: 10\%, 10\%, $9 \%$ and $9 \%$, respectively. In soil that had been treated with chicken manure, the relative abundance of almost all of the detected species varied from $2 \%$ to $7 \%$, and only a single dominant $(17 \%)$ species (Mortierella indohii) was observed. For this treatment, a total of seven species-Mortierella indohii, Cladorrhinum flexuosum, Mortierella sarnyensis, Humicola grisea, Solicoccozyma terricola, Apodus deciduus and Mortierella hyaline-represented more than half of the total sequences of the detected species. For the control soil, only Metarhizium anisopliae, Pseudogymnoascus verrucosus, Exophiala equina and Mortierella alpina were the most dominant species, and these species, in total, accounted for $56 \%$ of the fungal sequences with a relative abundance greater than $1 \%$ (Figure 7). According to the Venn diagram (Figure 8), consistent overlap patterns of the species clusters among the different treatments were obtained (Figure 7). 
Table 3. The relative abundance of the phylogenetic genus in the different amended soils, according to its relative abundance ( $\geq 1 \%)$ in each treatment.

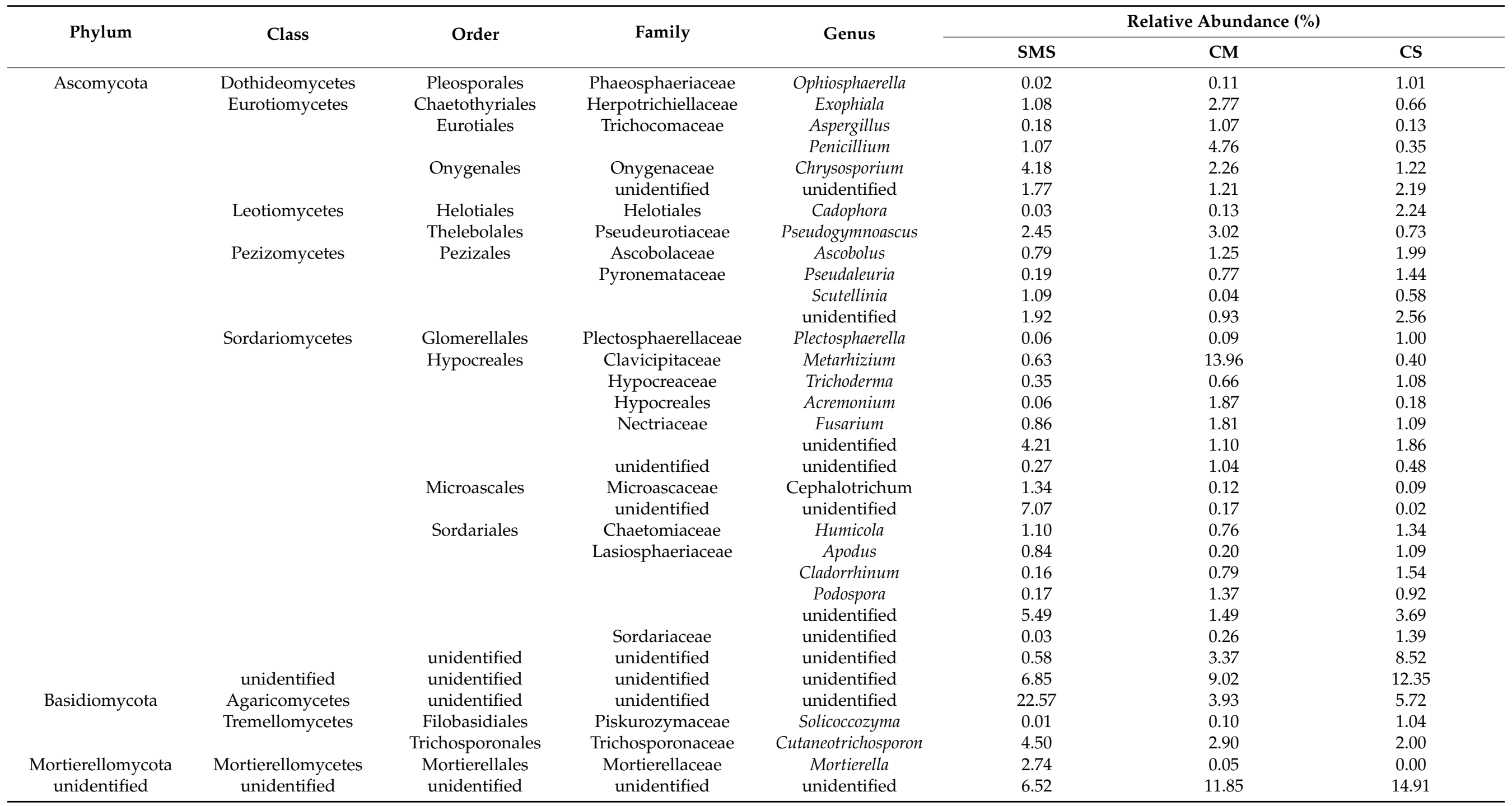




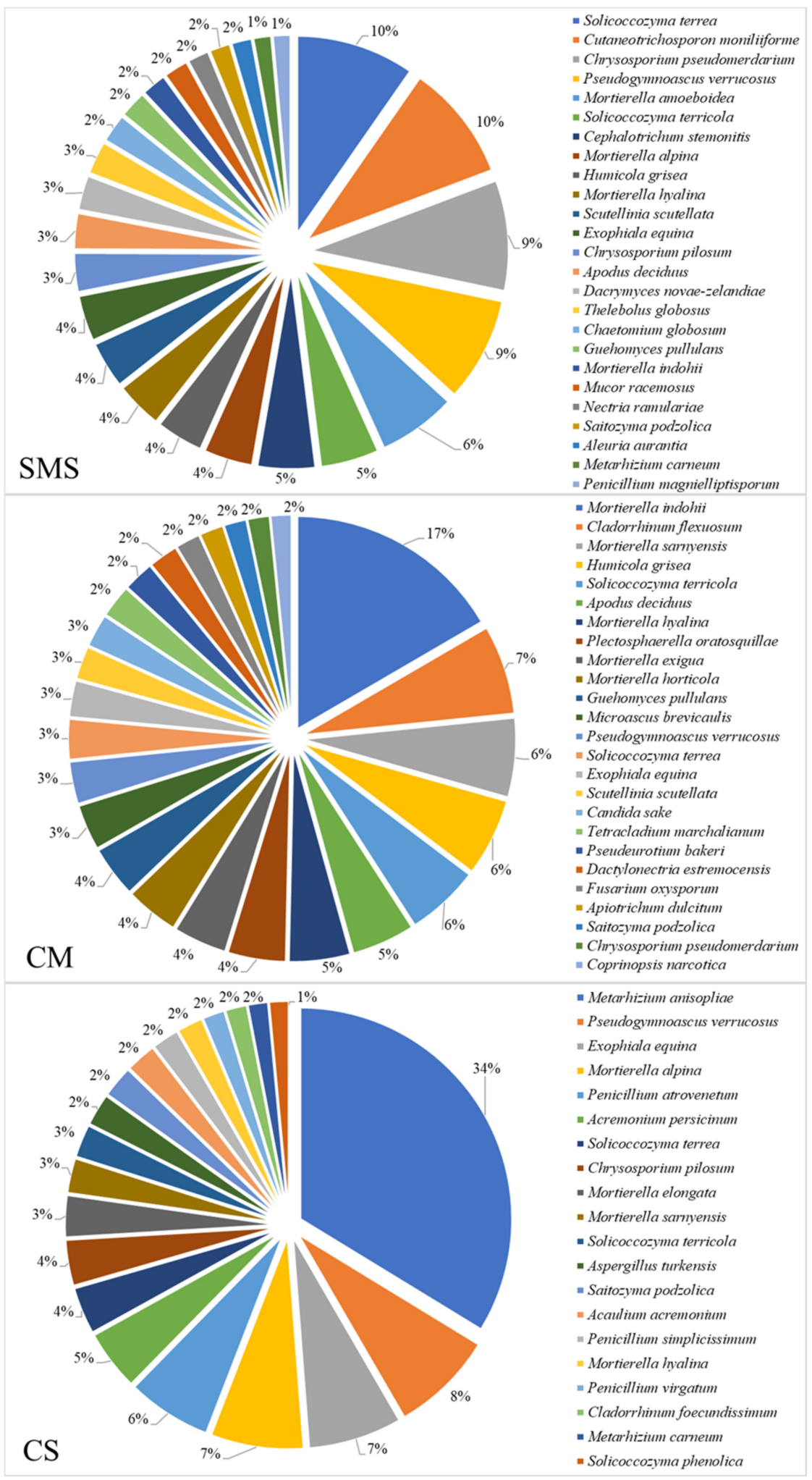

Figure 7. The relative abundance of soil fungal species, which constitute at least $1 \%$ among identified species, after the long-term organic treatment presented as core mycobiome. The percent of sequences classified to a fungal species for each treatment was as follows: $37.71 \%$ (SMS), 34.69\% (CM), 54.69\% (CS). SMS—spent mushroom substrate, CM—chicken manure, CS—control soil. Fungal communities were examined through next generation sequencing (NGS) of the ITS1 region using Illumina MiSeq technology. 


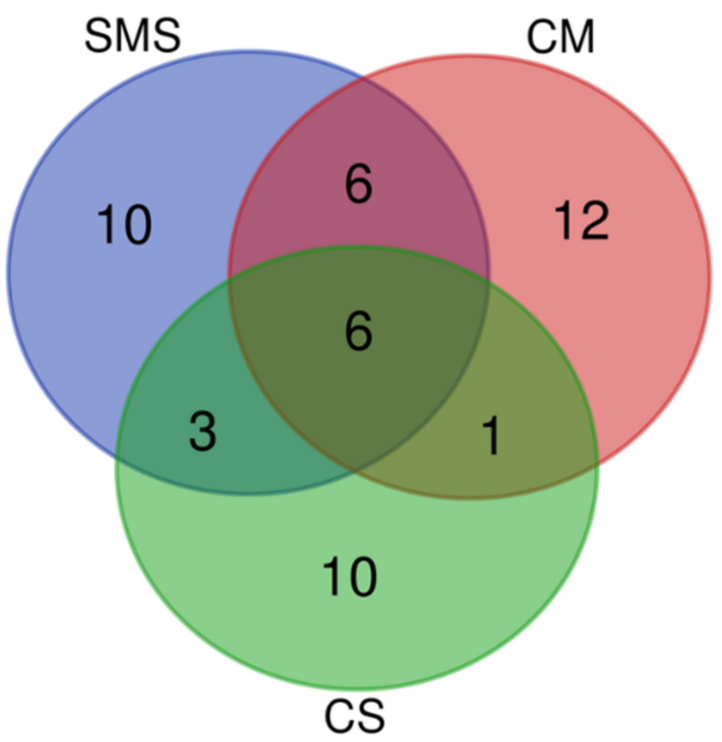

Figure 8. Venn diagram of fungal species in soil treatments, showing the number of shared and unique species in the treatments based on identified operational taxonomic units (OTUs) $\geq 1 \%$. The numbers in the overlapping circles show the species shared by two or three treatments of the fungal community and the intersections of the circles indicate the coexisting fungal genera in those treatments. SMS—spent mushroom substrate, CM—chicken manure, CS—control soil.

In the fungal community, 48 species were detected as a core mycobiota in all of the tested soil treatments. Only one species was shared by the respective communities of the chicken manure amended soil and the control soil. Three species were shared by the mycobiome of the spent mushroom substrate and the control soil. For the chicken manure and the spent mushroom substrate fertilized soil, a core mycobiota of six species were identified. According to the Venn diagram for the most abundant identified OTUs ( $\geq 1 \%)$, six species were common for all of the treatments, as well as 10,12 and 10 species were specific for SMS, CM and CS, respectively (Figure 8).

Functional guilds prediction of the fungal community included seven trophic modes (pathotroph, pathotroph-saprotroph, pathotroph-saprotroph-symbiotroph, pathotrophsymbiotroph, saprotroph, saprotroph-symbiotroph, symbiotroph) observed in all tested soil treatments. The two groups including saprotroph and saprotroph-symbiotroph were present in all tested treatments, but they were dominant for SMS- and CM-treated soils (Figure 9). The OTUs counts as well as relative abundances of the saprotrophs, saprotrophssymbiotrophs and pathotrophs-symbiotrophs in CS soil were at similar level (Figure 9). Moreover, based on FunGuild analysis it was observed that the relative abundance of some potentially pathogenic fungi including plant pathogens (Gibberella zeae, Mycosphaerella tassiana, Leptosphaeria sp., Slopeiomyces cylindrosporus, Sporothrix inflata) and animal pathogens (Exophiala equina) decreased after the application of SMS and CM (Table S7). Application of these exogenous organic matter caused an increase in the abundance of Cephalotrichum stemonitis and Penicillium aurantiogriseum, which according to FunGuild analysis was classified as a plant pathogen. Moreover, the counts of fungal parasite such as Syncephalis sp. and Trichoderma polysporum increased in soil treated with CM and SMS (Table S7). 

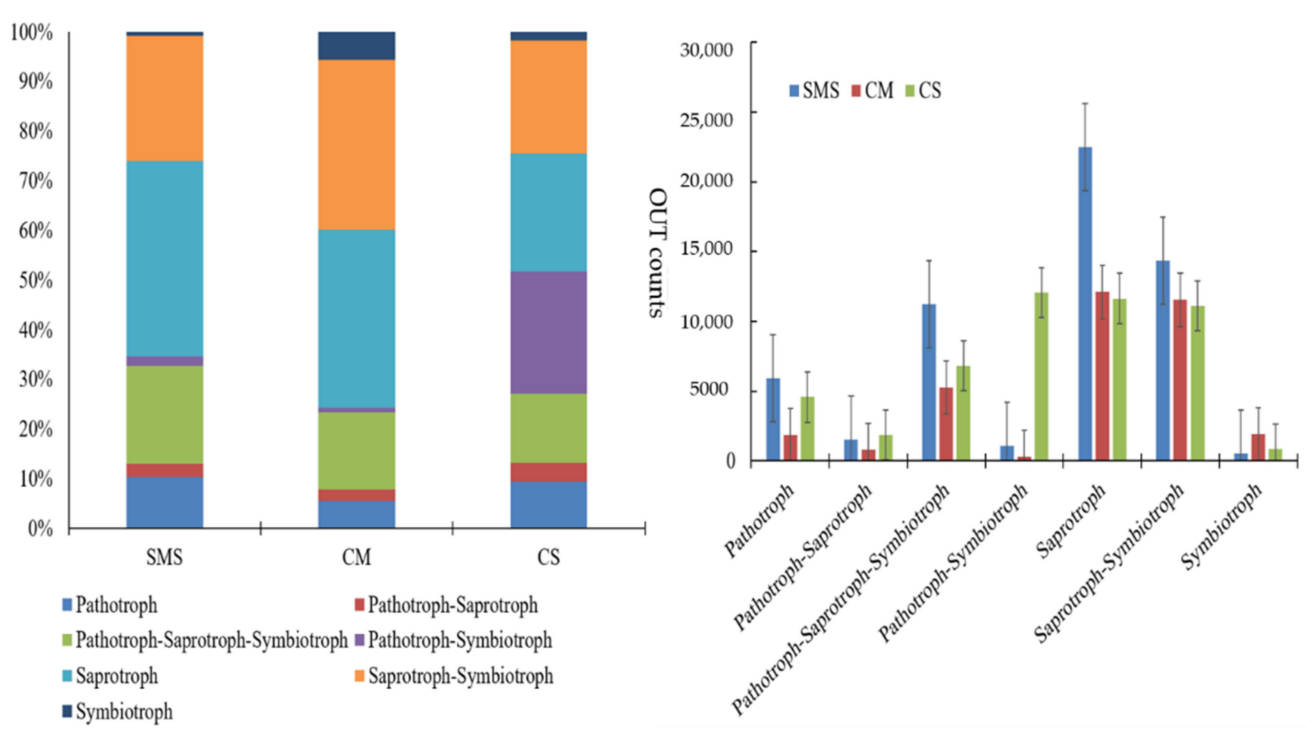

Figure 9. The relative abundance and OTUs counts for fungal functional groups (trophic modes) for each treatment based on FunGuild tool. SMS — spent mushroom substrate, CM-chicken manure, CS—control soil. Fungal communities were examined through next-generation sequencing (NGS) of the ITS1 region using Illumina MiSeq technology.

\section{Discussion}

\subsection{Effects of Additives on Soil Properties}

The spent mushroom substrates may enrich soils with organic matter, nitrogen, and carbonates, improving their fertility and preventing soil degradation [6]. To date, a large volume of research has indicated that soil properties-such as $\mathrm{pH}$, organic carbon content, bulk density, enzymatic and microbial activity-are improved by different organic additives [37-39]. Several studies have assessed the effects of organic matter application in the long-term experiments, but with additives such as biochar, composts, sewage sludge and farmyard manure [40-42]. The influence of spent mushroom substrate and chicken manure on soil properties has only been tested in a few short-term experiments [3-9]. From a comparison of the results between the short-term and our 20-year studies, it is apparent that the positive effects of spent mushroom substrate (SMS) and chicken manure (CM) on the soil characteristics-such as the content of nutrients, water, and organic carbonwere cumulative compared to control soil (CS). Similar effects were observed with the application of biochar $[43,44]$.

\subsection{Effects of Organic Additives on Soil Fungal Abundance}

To the best of our knowledge, this is the first such comprehensive report concerning changes in soil fungal community abundance and diversity as a result of the spent mushroom substrate and chicken manure treatment. Different molecular tools-including qPCR, DGGE, t-RFLP and NGS - were used to investigate the exogenous organic matter's (SMS, CM) effects on fungal communities. In order to obtain the complex responses of the fungal community to the application of the exogenous organic matter into the soil, we decided to combine a quantitative approach (qPCR) widely applied in microbial ecology to quantify the abundance of fungal gene markers within the environment [45], old-school reliable techniques for the screening of the diversity of fungal community and shifts and pattern changes (DGGE, t-RFLP) [16,46], tools for the identification of fungi based on T-RFs size (TRiFLe) [17], and high throughput sequencing, which provides insight into the soil fungal community structure, composition and functional guilds, and is a useful and effective approach for the characterization of the microbial communities [18,47]. Although, in the last three years, many papers concerning changes in the fungal community were published $[14,40,41,48,49]$, to date, no-one else has tested organic waste such as spent mushroom substrate and chicken manure. Moreover, the evaluation of the fungal commu- 
nity changes under the influence of different factors is relevant and important, but it has not yet been explained to a satisfactory extent. In this study, the soil fungal abundance increased with SMS and CM treatment; this result is consistent with a study showing that the application of organic matter promoted soil fungal growth $[40,48,50]$. The explanation for the increasing fungal abundance after SMS and CM treatment may be related to the changes in the soil environment caused by the addition of exogenous organic matter [40]; this may improve soil water retention, bulk density, and soil porosity, and may increase water repellence [51,52], $\mathrm{pH}$, nutrient and moisture contents [40], and therefore provide a better habitat for soil microorganisms [53,54].

\subsection{Effects of the Organic Additives on the Soil Fungal Community Structure}

Enhancing the level of understanding of the soil fungal community structure after the organic matter application is very important because these organisms constitute a significant part of the biodiversity and biomass in soils, and they also play an essential role in soil processes connected with the functioning of the ecosystem [55]. Most of the current knowledge concerning microbial diversity in the soil is related to bacteria; therefore, the information concerning fungal communities in soils is fragmentary and still needs to be improved.

The fungal community structure in arable and forest soils was also previously determined using pyrosequencing [56] and MiSeq [41] methods. In the present study, Ascomycota, Basidiomycota and Mortierellomycota were the top three phyla occurring in all of the treatments tested. This corresponded to the previous studies concerning agricultural soils $[41,57,58]$ and forest soil [59], in which Ascomycota and Basidiomycota were the two most abundant phyla. Ascomycota accounts for approximately $75 \%$ of all of the fungi described. Several of them were classified as litter decomposers, plant, animal, or human pathogens, endophytes and saprotrophs [55], as well as many Ascomycota representatives, which are also symbionts for plants $[59,60]$. However, Basidiomycota includes some of the most familiar fungi that are widely known for the production of large fruit bodies, as well as fungi that are plant parasites, cause wood decay, and are litter decomposers. This group may be helpful to plants due to their symbiotic relationship with plant roots and their role in improving the storage of water, minerals, and metabolites [61]. Mortierellomycota was another phylum identified in all of the soil treatments, but with a lower abundance compared to Ascomycota and Basidiomycota. Fungi from this phylum are commonly found in various environments, and are found in the bulk soil, the rhizosphere, and plant tissues; therefore, they play a very important role in the carbon cycle and organic matter decomposition. They are also known as plant growth-promoting fungi [62]. In contrast to our results, in Amazon farmland, the other phyla were most abundant, rather than Ascomycota [63], but the results were based on other markers than ITS1. In our study, the relative abundance of Glomeromycota was lower in the tested soil treatments than in the studies of other researchers $[49,64]$. However, it is worth stressing that although the internal transcribed spacer (ITS) region is the accepted DNA barcode of fungi [65], Glomeromycota, being the most widespread fungal symbionts of plants [66], are better characterized by alternative markers, such as the $18 \mathrm{~S}$ rRNA region specific to arbuscular mycorrhizal fungi (AMF) [67]. Therefore, that Glomeromycota is probably underrepresented in our dataset targeting the ITS1 region. Moreover, because only $30-35 \%$ of Glomeromycetes are present in databases [68], perhaps the majority of AMF are not identifiable from environmental samples [67].

Ectomycorrhizal fungi usually dominate the forest soil [69]. Tremellomycetes and Dothideomycetes were the dominant fungal classes in forest soils [70], whereas Sordariomycetes and Dothideomycetes are the most abundant classes in agricultural soil [41]. In the present study, Sordariomycetes, Tremellomycetes, Mortierellomycetes and Eurotiomycetes were dominant for all of the soil treatments (SMS, CM, CS). As reported by [71], Sordariomycetes increased with N's addition to the soil. Moreover, [41] observed an increase in this class of fungi after the incorporation of inorganic fertilizer and manure. These 
observations may explain the highest abundance of Sordariomycetes in all of the tested treatments, in the control soil with mineral fertilization, and in the treatments with chicken manure and spent mushroom substrate in our study.

The most evident differences in the fungal community were the higher relative abundance of the Tremellomycetes and Pezizomycetes classes after the application of SMS and Mortierellomycetes, Leotiomycetes and Agaricomycetes following CM treatment. Tremellomycetes are a nutritionally heterogeneous group that includes saprotrophs, animal parasites and the fungicolous species of yeasts [61,72]. Whereas, most Pezizomycetes are saprotrophic species with the ability to degrade the components of plant cell walls and play an important role in organic matter decomposition [69]. Therefore, an increase in the relative abundance of this class in SMS-amended soil may be stimulated by an increase in the level of appropriate substrates for degradation after the addition of organic additives to the soil and mobilization of nutrients from organic substrates. That is a way, they may benefit plant growth [49]. The Mortierellomycetes class, stimulated by the application of CM, includes both saprobes and root endophytes [73]. Nevertheless, those fungi, as soil-inhabiting saprobic organisms, participate in the decomposition of organic matter. Many species possess the ability to accelerate the organic compound transformation and fatty acids production [74]. Moreover, it was found that Mortierellales representatives increased in treatments fertilized with phosphorus biofertilizer [75]. The class of fungi which decreased after SMS and CM addition to the soil was Dothideomycetes, which is involved in the decay of cell walls [14] and is important in biomass degradation, and as the saprophyte is engaged in carbon cycling [76]. However, representatives of this class infect almost every major crop [77], and the class includes important fungal pathogens of plant involved in the production of food, feed, fiber and biofuel [78].

Although the application of organic matter decreases the degree of antagonism and mutualism in the soil [79], it can also stimulate the growth of fungi important to maintain the ecological functions of soil and the health of ecosystems. The relative abundance of Chrysosporium, Ascobolus, Fusarium, Solicoccozyma and Mortierella was dominant for the CM treatment, whereas for SMS treated soil Chrysosporium, Humicola, Solicoccozyma and Mortierella prevailed. Moreover, we found that the abundance of Humicola and Apodus increased as a consequence of both SMS and CM treatments. These findings suggest that these organisms were very sensitive to the addition of SMS and CM. Some of these fungi are known to be potentially pathogenic for plants and can cause a reduction in plant growth, as well as they can participate in decomposition processes serving one of the most important ecological roles of fungi $[49,60]$.

It is worth to mention that a high relative abundance of Trichoderma was observed in CM-treated soil based on t-RFs fragments and OTUs sequences in both t-RFLP and NGS molecular approaches. Moreover, both these molecular techniques confirmed the presence of the most abundant Metarhizium representatives in control soil. Therefore, molecular approaches, especially metagenomics, were an effective and sensitive tool for fungal community characterization of soil enriched with chicken manure and spent mushroom substrate providing comparative results concerning diversity indices and mycobiota composition across the treatments. Obtained results are important in the context of agriculture management including organic farming, due to relationships and communication of microbes in the soil environment. As it was previously underlined, core microbiota is a part of microbiome study, important for understanding stability, plasticity and functioning across complex microbial assemblages [80].

\subsection{Effects of Organic Additives on Soil-Borne Pathogens and Functional Guild Groups}

The application of organic additives was proposed as a strategy for the control of diseases caused by soil-borne pathogens [41]. One of the most noteworthy findings in this study is the observation of a decrease in the relative abundance of Metarhizium, Acremonium and some fungi belonging to the Leotiomycetes class with the addition of SMS and CM. Many species of Metarhizium are entomopathogenic fungi [81]. However, Acremonium 
belonging to the Ascomycota phylum is also a common soil fungus, which can also grow on decaying wood or tree bark. Many species from this genus are known to plant pathogens and cause plant diseases [82]. Leotiomycetes are ecologically diverse and include plant pathogens [73]. Our findings suggest that the long-term SMS and CM treatment decreases the population of entomopathogenic and some soil-borne plant pathogenic fungi, and may suppress crop disease occurrence. However, to the best of our knowledge, this is the first direct evidence that the population of some soil-borne plant pathogenic fungi is decreased by SMS and CM treatment, based on a next generation sequencing method and further studies is required.

Although the positive impact of the spent mushroom substrate and chicken manure on the reduction of some soil-borne fungal pathogens has been confirmed, the relative abundance of Fusarium, containing many crop pathogen species [83], was at the same level for all of the treatments tested. However, it is necessary to underline that Fusarium genus does not only comprise plant pathogenic species but also nonpathogenic symbiotrophs [84], and can also contain plant promoting species [85]. Our findings suggest that the application of SMS and CM reduced the relative abundance of some potentially pathogenic fungi such as Gibberella zeae, Mycosphaerella tassiana, Leptosphaeria sp., Slopeiomyces cylindrosporus, Sporothrix inflata and Exophiala equina and caused an increase in the abundance of Cephalotrichum stemonitis and Penicillium aurantiogriseum, which are plant pathogens. Therefore, in this context the effect of the waste exogenous organic matter used is ambiguous and requires further research. However, it is worth to mention that a trend in phytopathogens reduction in soil microbial community after SMS application was visible, therefore this type of exogenous organic matter could be considered as a carrier for biopreparations in agroecology.

\section{Conclusions}

The study demonstrated that long-term (20 years) spent mushroom substrate (SMS) and chicken manure $(\mathrm{CM})$ treatment increased soil fungal abundance and changed the fungal community structure at the genus and species level, but not completely at the phylum level. It was found that SMS and CM addition decreased the relative abundance of several OTUs of potential crop pathogens.

In addition, the changes in the soil fungal community abundance were related to the total soil organic carbon and labile organic carbon contents, which suggests that the longterm influence of exogenous organic matter (SMS, CM) on the soil fungal community was directly and indirectly affected by organic impact and soil property changes, respectively.

This study also provides more insights into the response of the soil fungal community composition to different types of organic matter addition, which should prove helpful in managing the soil mycobiome for sustainable agricultural productivity. The molecular approaches allowed for a description of fungal diversity and community composition, as well as functional guild group occurrence in response to the long-term application of spent mushroom substrate and chicken manure. However, further research, including a consideration of the methodical aspect of throughput sequencing methods, is still required in order to identify the unknown portion of the as-yet unidentified fungi occurring in the soil environment.

Supplementary Materials: The following are available online at https:/ / www.mdpi.com/2073-439 5/11/3/410/s1, Figure S1: The map showing the location of the treatments and the distance between fields. SMS-spent mushroom substrate; CM-chicken manure; CS-control soil. https://umap. openstreetmap.fr/pl/map/cs-sms-cm_550327 (accessed on 19 February 2021). Map created with uMap https:/ / umap.openstreetmap.fr / (accessed on 19 February 2021), Figure S2: The amplification plot (A) and the melting curve (B) of the standard and negative template control obtained from the quantification of the fungal abundance. The blue circle underlines the negative template control (NTC), Figure S3: The example of a gel picture showing the PCR-products ranged from $\sim 500 \mathrm{bp}$ to $\sim 700 \mathrm{bp}$, that were used for nested PCR to obtain amplicons for DGGE analysis. SMS-spent mushroom substrate; CM-chicken manure; CS-control soil, M-DNA marker used as weight standard 
in the range of 100-10,000 bp, Figure S4: The OTUs number of soil fungal species after the long-term organic treatment. SMS-spent mushroom substrate; CM-chicken manure; CS-control soil of control soil. The OTUs with more relative abundance than $0.5 \%$ were presented. Fungal communities were examined through the next-generation sequencing (NGS) of the ITS1 region using Illumina MiSeq technology, Table S1: Similarity matrix-DGGE analysis of fungal community. SMS-spent mushroom substrate; CM-chicken manure; CS-control soil, Table S2: Richness (number of ribotypes; R), Shannon diversity (H), Simpson's diversity (S) indices of fungal populations in the soil treatments based on t-RFLP analysis. SMS-spent mushroom substrate; CM-chicken manure; CS-control soil, Table S3: Distribution of different $\mathrm{t}$-RFs fragments inside various treatments enriched with exogenous organic matter. SMS-spent mushroom substrate; CM-chicken manure; CS-control soil, Table S4: Fungal genus in treatments tested. Prediction was performed as in silico analysis using TRiFLe package. SMS-spent mushroom substrate; CM-chicken manure; CS-control soil, Table S5: Compilation of nextgeneration sequencing readings of fungal ITS1 for particular taxonomic level in treatments tested. SMS-spent mushroom substrate; CM-chicken manure; CS-control soil, Table S6: Relative abundance (RA \%), individual identification (n) and sequences number (reads) of dominated phylogenetic genus in soil with different treatments. SMS-spent mushroom substrate; CM-chicken manure; CScontrol soil, Table S7: Functional guilds for three main trophic modes: patotrophs, symbiotrophs and saprotrophs in soil amended with waste exogenous organic matter.

Author Contributions: Conceptualization, M.F., J.L. and B.U.; methodology, M.F., G.P., J.P., A.G., K.O.; investigation, M.F., G.P., J.P., A.G., K.O.; writing-original draft preparation, M.F.; writingreview and editing, M.F., G.P., J.P., A.G., K.O., J.L., B.U.; visualization, M.F., G.P., A.G., K.O.; supervision, M.F. and J.L.; All authors have read and agreed to the published version of the manuscript.

Funding: This research was funded by HORIZON 2020, European Commission, Programme H2020SFS-2015-2: Soil Care for profitable and sustainable crop production in Europe, project No. 677407 (SoilCare, 2016-2021).

Institutional Review Board Statement: Not applicable.

Informed Consent Statement: Not applicable.

Data Availability Statement: The obtained sequences via next generation sequencing are deposited in the SRA database under the following accession number: PRJNA430503 (https:/ /www.ncbi. nlm.nih.gov/sra/PRJNA430503 accessed on 19 February 2021). The other data are presented in Supplementary Materials.

Acknowledgments: The next generation sequencing analysis was performed in Genomed S.A. (Warsaw, Poland). We would like to thank Anna Wasowska for bioinformatics consultations. Figure S1-Map data copyrighted OpenStreetMap contributors under Open Database Licence and available from https: / / www.openstreetmap.org (accessed on 19 February 2021).

Conflicts of Interest: The authors declare no conflict of interest.

\section{References}

1. Frąc, M.; Ziemiński, K. Methane fermentation process for utilization of organic waste. Int. Agrophys. 2012, 26, 317-330. [CrossRef]

2. Jezierska-Tys, S.; Frac, M. Impact of dairy sewage sludge on enzymatic activity and inorganic nitrogen concentrations in the soils. Int. Agrophys. 2009, 23, 31-37.

3. Marín-Benito, J.M.; Sánchez-Martín, J.M.; Rodríguez-Cruz, M.S. Impact of spent mushroom substrates on the fate of pesticides in soil, and their use for preventing and/or controlling soil and water contamination: A review. Toxics 2016, 4, 17. [CrossRef] [PubMed]

4. Becher, M. Chemical composition of spent mushroom substrate after cultivation of Agaricus bisporus as a waste organic material. Ekon. Sr. 2013, 4, 207-213. (In Polish)

5. Ahlawat, O.P.; Sagar, M.P. Management of Spent Mushroom Substrate Technical Bulletin; National Research Centre for Mushroom, Indian Council of Agricultural Research: Solan, India, 2007.

6. Becher, M.; Banach-Szott, M.; Godlewska, A. Organic Matter Properties of Spent Button Mushroom Substrate in the Context of Soil Organic Matter Reproduction. Agronomy 2021, 11, 204. [CrossRef]

7. Owaid, M.N.; Abed, I.A.; Al-Saeedi, S.S.S. Applicable properties of the bio-fertilizer spent mushroom substrate in organic systems as a byproduct from the cultivation of Pleurotus spp. Inform. Process. Agric. 2017, 4, 78-82. [CrossRef]

8. Marques, E.L.S.; Martos, E.T.; Souza, R.J.; Silva, R.; Zied, D.C.; Souza Dias, E. Spent mushroom compost as a substrate for the production of lettuce seedlings. J. Agric. Sci. 2014, 6, 138-143. [CrossRef] 
9. Remya, J.S.; Beena, S. Antagonistic potential of fungal microflora from spent mushroom substrate against soil borne pathogens of ginger. Int. J. Appl. Pur. Sci. Agric. 2015, 1, 93-101.

10. Medina, E.; Paredes, C.; Bustamante, M.A.; Moral, R.; Moreno-Caselles, J. Relationships between soil physico-chemical, chemical and biological properties in a soil amended with spent mushroom substrate. Geoderma 2012, 173, 152-161. [CrossRef]

11. Chen, Z.; Jiang, X. Microbiological safety of chicken litter or chicken litter-based organic fertilizers: A review. Agriculture 2014, 4, 1-29. [CrossRef]

12. Quang, N.H. Long-Term Effects of Land Application of Poultry Manure on Crop Production, and Soil and Water Quality Under a Corn-Soybean Rotation System in Iowa. Master's Thesis, Iowa State University, Ames, IA, USA, 2010; pp. 1-95.

13. Fierer, N.; Lauber, C.L.; Ramirez, K.S.; Zaneveld, J.; Bradford, M.A.; Knight, R. Comparative metagenomic, phylogenetic and physiological analyses of soil microbial communities across nitrogen gradients. ISME J. 2012, 6, 1007-1017. [CrossRef]

14. Zhou, J.; Jiang, X.; Zhou, B.; Zhao, B.; Ma, M.; Guan, D.; Li, J.; Chen, S.; Cao, F.; Shen, D.; et al. Thirty four years of nitrogen fertilization decreases fungal diversity and alters fungal community composition in black soil in northeast China. Soil Biol. Biochem. 2016, 95, 135-143. [CrossRef]

15. Klaubauf, S.; Inselsbacher, E.; Zechmeister-Boltenstern, S.; Wanek, W.; Gottsberger, R.; Strauss, J.; Gorfer, M. Molecular diversity of fungal communities in agricultural soils from Lower Austria. Fung. Div. 2010, 44, 65-75. [CrossRef] [PubMed]

16. De Vrieze, J.; Ijaz, U.Z.; Saunders, A.M.; Theuerl, S. Terminal restriction fragment length polymorphism is an "old school" reliable technique for swift microbial community screening in anaerobic digestion. Sci. Rep. 2018, 8, 1-12. [CrossRef]

17. Junier, P.; Junier, T.; Witzel, K.P. TRiFLe, a Program for in silico terminal restriction fragment length polymorphism analysis with user-defined sequence sets. Appl. Environ. Microbiol. 2008, 74, 6452-6456. [CrossRef] [PubMed]

18. Cao, Y.; Fanning, S.; Proos, S.; Jordan, K.; Srikumar, S. A Review on the Applications of Next Generation Sequencing Technologies as Applied to Food-Related Microbiome Studies. Front. Microbiol. 2017, 8, 1-16. [CrossRef] [PubMed]

19. Rincon-Florez, V.A.; Carvalhais, L.C.; Schenk, P.M. Culture-Independent Molecular Tools for Soil and Rhizosphere Microbiology. Diversity 2013, 5, 581-612. [CrossRef]

20. WRB IUSS Working Group. World Reference Base for Soil Resources 2014, update 2015. International soil classification system for naming soils and creating legends for soil maps. In World Soil Resources Reports; FAO: Rome, Italy, 2015.

21. Usowicz, B.; Hajnos, M.; Sokołowska, Z.; Józefaciuk, G.; Bowanko, G.; Kossowski, J. Spatial variability of physical and chemical soil properties in a field and commune scale. Acta Agrophysica Monogr. 2004, 3, 90. (In Polish)

22. Kalembasa, D.; Majchrowska-Safaryan, A. Fraction of heavy metals in the beds after the cultivation mushroom from mushroom factor. Ochr. Sr. Zasobów Nat. 2009, 41, 1-6. (In Polish)

23. Polish Standard. Determination of Available Phosphorus in Mineral Soils; PN-R-04023:1996; Polish Committee for Standardization: Warsaw, Poland, 1996.

24. Polish Standard. Determination of Available Potassium in Mineral Soils; PN-R-04022:1996/Az1:2002; Polish Committee for Standardization: Warsaw, Poland, 1996.

25. Polish Standard. Determination of Available Magnesium in Soils; PN-R-04020:1994/Az1:2004; Polish Committee for Standardization: Warsaw, Poland, 1994.

26. Ostrowska, A.; Gawliński, S.; Szczubiałka, Z. Analyses and Evaluation Methods of Soil and Plants; Institute of Environmental Protection: Warsaw, Poland, 1991; p. 334. (In Polish).

27. Oszust, K.; Frąc, M.; Gryta, A.; Bilińska, N. The influence of ecological and conventional plant production systems on soil microbial quality under hops (Humulus lupulus). Int. J. Mol. Sci. 2014, 15, 9907-9923. [CrossRef] [PubMed]

28. White, T.J.; Bruns, T.; Lee, S.; Taylor, J. Amplification and direct sequencing of fungal ribosomal RNA genes for phylogenetics. In PCR Protocols, A Guide to Methods and Applications; Innis, M., Gelfand, D., Shinsky, J., White, T., Eds.; Academic Press: New York, NY, USA, 1990; pp. 315-322.

29. Korabecna, M. The variability in the fungal ribosomal DNA (ITS1, ITS2, and $5.8 \mathrm{~S}$ rRNA gene): Its biological meaning and application in medical mycology. Com. Cur. Res. Edu. Top. Trend. Appl. Microbiol. 2007, 108, 783-787. [CrossRef]

30. Manter, D.K.; Vivanco, J.M. Use of the ITS primers, ITS1F and ITS4, to characterize fungal abundance and diversity in mixedtemplate samples by qPCR and length heterogeneity analysis. J. Microbiol. Met. 2007, 71, 7-14. [CrossRef]

31. National Center for Biotechnology Information. Available online: https:/ / www.ncbi.nlm.nih.gov (accessed on 21 January 2021).

32. Schmidt, P.A.; Bálint, M.; Greshake, B.; Bandowa, C.; Römbke, J.; Schmitt, I. Illumina metabarcoding of a soil fungal community. Soil Biol. Biochem. 2013, 65, 128-132. [CrossRef]

33. Vilgalys Mycology Lab—Duke University. Available online: https://sites.duke.edu/vilgalyslab/rdna_primers_for_fungi (accessed on 21 January 2021).

34. Caporaso, J.G.; Kuczynski, J.; Stombaugh, J.; Bittinger, K.; Bushman, F.D.; Costello, E.K.; Fierer, N.; Peña, A.G.; Goodrich, J.K.; Gordon, J.I.; et al. QIIME allows analysis of high-throughput community sequencing data. Nat. Methods 2010, 7, 335-336. [CrossRef] [PubMed]

35. Aronesty, E. ea-utils: Command-Line Tools for Processing Biological Sequencing Data. 2011. Available online: http://code. google.com/p/ea-utils (accessed on 21 January 2021).

36. Nguyen, N.H.; Song, Z.; Bates, S.T.; Branco, S.; Tedersoo, L.; Menke, J.; Schilling, J.S.; Kennedy, P.G. FUNGuild: An open annotation tool for parsing fungal community datasets by ecological guild. Fungal Ecol. 2016, 20, 241-248. [CrossRef] 
37. Islam, M.A.; Islam, S.; Akter, A.; Rahman, M.H.; Nandwani, D. Effect of organic and inorganic fertilizers on soil properties and the growth, yield and quality of tomato in Mymensingh, Bangladesh. Agriculture 2017, 7, 31. [CrossRef]

38. Oszust, K.; Frąc, M.; Lipiec, J. Soil microbial functionality in response to dairy sewage sludge and mineral fertilisers application under winter rape. Int. J. Environ. Sci. Technol. 2015, 12, 3675-3684. [CrossRef]

39. Lehmann, J.; Rillig, M.C.; Thies, J.; Masiello, C.A.; Hockaday, W.C.; Crowley, D. Biochar effects on soil biota-a review. Soil Biol. Biochem. 2011, 43, 1812-1836. [CrossRef]

40. Yao, Q.; Liu, J.; Yu, Z.; Li, Y.; Jin, J.; Liu, X.; Wang, G. Three years of biochar amendment alters soil physiochemical properties and fungal community composition in a black soil of northeast China. Soil Biol. Biochem. 2017, 110, 56-67. [CrossRef]

41. Ding, J.; Jiang, X.; Guan, D.; Zhao, B.; Ma, M.; Zhou, B.; Cao, F.; Yang, X.; Li, L.; Li, J. Influence of inorganic fertilizer and organic manure application on fungal communities in a long-term field experiment of Chinese Mollisols. Appl. Soil Ecol. 2017, 111, 114-122. [CrossRef]

42. Bastida, F.; Torres, I.F.; Hernandez, T.; García, C. The impacts of organic amendments: Do they confer stability against drought on the soil microbial community? Soil Biol. Biochem. 2017, 113, 173-183. [CrossRef]

43. Gul, S.; Whalen, J.K.; Thomas, B.W.; Sachdeva, V.; Deng, H.Y. Physico-chemical properties and microbial responses in biocharamended soils: Mechanisms and future directions. Agric. Ecosyst. Environ. 2015, 206, 46-59. [CrossRef]

44. Gul, S.; Whalen, J.K. Biochemical cycling of nitrogen and phosphorus in biochar-amended soils. Soil Biol. Biochem. 2016, 103, 1-15. [CrossRef]

45. Smith, C.J.; Osborn, A.M. Advantages and limitations of quantitative PCR(Q-PCR)-based approaches in microbial ecology. FEMS Microbiol. Ecol. 2009, 67, 6-20. [CrossRef] [PubMed]

46. Gryta, A.; Frąc, M.; Oszust, K. Community shift in structure and functions across soil profile in response to organic waste and mineral fertilization strategies. Appl. Soil Ecol. 2019, 143, 55-60. [CrossRef]

47. Hannula, S.E.; Ma, H.; Pérez-Jaramillo, J.E.; Pineda, A.; Bezemer, T.M. Structure and ecological function of the soil microbiome affecting plant-soil feedbacks in the presence of a soil-borne pathogen. Environ. Microbiol. 2020, 22, 660-676. [CrossRef]

48. Thomson, B.C.; Tisserant, E.; Plassart, P.; Uroz, S.; Griffiths, R.I.; Hannula, S.E.; Buee, M.; Mougel, C.; Ranjard, L.; Van Veen, J.A.; et al. Soil conditions and land use intensification effects on soil microbial communities across a range of European field sites. Soil Biol. Biochem. 2015, 88, 403-413. [CrossRef]

49. Wang, J.; Song, Y.; Ma, T.; Raza, W.; Li, J.; Howland, J.G.; Huang, Q.; Shen, Q. Impacts of inorganic and organic fertilization treatments on bacterial and fungal communities in a paddy soil. Appl. Soil Ecol. 2017, 112, 42-50. [CrossRef]

50. Quilliam, R.S.; Glanville, H.C.; Wade, S.C.; Jones, D.L. Life in the 'charosphere'-does biochar in agricultural soil provide a significant habitat for microorganisms? Soil Biol. Biochem. 2013, 65, 287-293. [CrossRef]

51. Lipiec, J.; Brzezinska, M.; Turski, M.; Szarlip, P.; Frąc, M. Wettability and biogeochemical properties of the drilosphere and casts of endogeic earthworms in pear orchard. Soil Till. Res. 2015, 145, 55-61. [CrossRef]

52. Król, A.; Lipiec, J.; Frąc, M. The effect of dairy sewage sludge amendment on repellency and hydraulic conductivity of soil aggregates from two depths of Eutric Cambisol. J. Plant Nutr. Soil Sci. 2015, 178, 270-277. [CrossRef]

53. Frąc, M.; Oszust, K.; Lipiec, J.; Jezierska-Tys, S.; Nwaichi, E.O. Soil microbial functional and fungal diversity as influenced by municipal sewage sludge accumulation. Int. J. Environ. Res. Public Health 2014, 11, 8891-8908. [CrossRef] [PubMed]

54. Ameloot, N.; Graber, E.R.; Verheijen, F.G.A.; De Neve, S. Interactions between biochar stability and soil organisms: Review and research needs. Eur. J. Soil Sci. 2013, 64, 379-390. [CrossRef]

55. Narendrula-Kotha, R.; Nkongolo, K.K. Bacterial and fungal community structure and diversity in a mining region under long-term metal exposure revealed by metagenomics sequencing. Ecol. Genet. Genom. 2017, 2, 13-24. [CrossRef]

56. Brown, S.P.; Jumpponen, A. Contrasting primary successional trajectories of fungi and bacteria in retreating glacier soils. Mol. Ecol. 2014, 23, 481-497. [CrossRef]

57. Feng, Y.; Yu, Y.; Tang, H.; Zu, Q.; Zhu, J.; Lin, X. The contrasting responses of soil microorganisms in two rice cultivars to elevated ground-level ozone. Environ. Pollut. 2015, 197, 195-202. [CrossRef] [PubMed]

58. Su, P.; Lou, J.; Brookes, P.C.; Luo, Y.; He, Y.; Xu, J. Taxon-specific responses of soil microbial communities to different soil priming effects induced by addition of plant residues and their biochars. J. Soils Sediments 2017, 17, 674-684. [CrossRef]

59. Egidi, E.; Delgado-Baquerizo, M.; Plett, J.M.; Wang, J.; Eldridge, D.J.; Bardgett, R.D.; Maestre, F.T.; Singh, B.K. A few Ascomycota taxa dominate soil fungal communities worldwide. Nat. Commun. 2019, 10, 2369. [CrossRef] [PubMed]

60. Frąc, M.; Hannula, S.E.; Belka, M.; Jędryczka, M. Fungal biodiversity and their role in soil health. Front. Microbiol. 2018, 9 , 707. [CrossRef]

61. Millanes, A.M.; Diederich, P.; Ekman, S.; Wedin, M. Phylogeny and character evolution in the jelly fungi (Tremellomycetes, Basidiomycota, Fungi). Mol. Phylogen. Evol. 2011, 61, 12-28. [CrossRef] [PubMed]

62. Ozimek, E.; Hanaka, A. Mortierella Species as the Plant Growth-Promoting Fungi Present in the Agricultural Soils. Agriculture 2021, 11, 7. [CrossRef]

63. Fracetto, G.G.M.; Azevedo, L.C.B.; Fracetto, F.J.C.; Andreote, F.D.; Lambais, M.R.; Pfenning, L.H. Impact of Amazon land use on the community of soil fungi. Sci. Agric. 2013, 70, 59-67. [CrossRef]

64. Wu, L.; Chen, J.; Wu, H.; Wang, J.; Wu, Y.; Lin, S.; Khan, M.U.; Zhang, Z.; Lin, W. Effects of consecutive monoculture of Pseudostellaria heterophylla on soil fungal community as determined by pyrosequencing. Sci. Rep. 2016, 6, 1-10. [CrossRef] [PubMed] 
65. Schoch, C.L.; Seifert, K.A.; Huhndorf, S.; Robert, V.; Spouge, J.L.; Levesque, C.A.; Chen, W.; Fungal Barcoding Consortium. Nuclear ribosomal internal transcribed spacer (ITS) region as a universal DNA barcode marker for Fungi. Proc. Natl. Acad. Sci. USA 2012, 109, 6241-6246. [CrossRef]

66. Brachmann, A.; Parniske, M. The Most Widespread Symbiosis on Earth. PLoS Biol. 2006, 4, e239. [CrossRef]

67. Hart, M.M.; Aleklett, K.; Chagnon, P.-L.; Egan, C.; Ghignone, S.; Helgasson, T.; Lekberg, Y.; Öpik, M.; Pickles, B.J.; Waller, L. Navigating the labyrinth: A guide to sequence-based, community ecology of arbuscular mycorrhizal fungi. New Phytol. 2015, 207, 235-247. [CrossRef] [PubMed]

68. George, P.B.L.; Creer, S.; Griffiths, R.I.; Emmett, B.A.; Robinson, D.A.; Jones, D.L. Primer and Database Choice Affect Fungal Functional but Not Biological Diversity Findings in a National Soil Survey. Front. Environ. Sci. 2019, 7, 173. [CrossRef]

69. Tedersoo, L.; Arnold, A.E.; Sen, K.H. Novel aspects in the life cycle and biotrophic interactions in Pezizomycetes (Ascomycota, Fungi). Mol. Ecol. 2013, 22, 1488-1493. [CrossRef]

70. Liu, J.; Sui, Y.; Yu, Z.; Shi, Y.; Chu, H.; Jin, J.; Liu, X.; Wang, G. Soil carbon content drives the biogeographical distribution of fungal communities in the black soil zone of northeast China. Soil Biol. Biochem. 2015, 83, 29-39. [CrossRef]

71. Mueller, R.C.; Belnap, J.; Kuske, C.R. Soil bacterial and fungal community responses to nitrogen addition across soil depth and microhabitat in an arid shrubland. Front. Microbiol. 2015, 6, 1-11. [CrossRef]

72. Liu, X.Z.; Wang, Q.M.; Göker, M.; Groenewald, M.; Kachalkin, A.V.; Lumbsch, H.T.; Millanes, A.M.; Wedin, M.; Yurkov, A.M.; Boekhout, T.; et al. Towards an integrated phylogenetic classification of the Tremellomycetes. Stud. Mycol. 2015, 81, 85-147. [CrossRef]

73. Berbee, M.L. The phylogeny of plant and animal pathogens in the Ascomycota. Phys. Mol. Plant Pathol. 2001, 59, 165-187. [CrossRef]

74. Wagner, L.; Stielow, B.; Hoffmann, K.; Petkovits, T.; Papp, T.; Vágvölgyi, C.; de Hoog, G.S.; Verkley, G.; Voigt, K. A comprehensive molecular phylogeny of the Mortierellales (Mortierellomycotina) based on nuclear ribosomal DNA. Persoonia 2013, 30 , 77-93. [CrossRef]

75. Mącik, M.; Gryta, A.; Sas-Paszt, L.; Frąc, M. The Status of Soil Microbiome as Affected by the Application of Phosphorus Biofertilizer: Fertilizer Enriched with Beneficial Bacterial Strains. Int. J. Mol. Sci. 2020, 21, 8003. [CrossRef]

76. Goodwin, S.B.; Kema, G.H. Gearing up for comparative genomics: Analyses of the fungal class Dothideomycetes. New Phytol. 2009, 183, 250-254. [CrossRef]

77. Schoch, C.L.; Crous, P.W.; Groenewald, J.Z.; Boehm, E.W.; Burgess, T.I.; de Gruyter, J.; de Hoog, G.S.; Dixon, L.J.; Grube, M.; Gueidan, C.; et al. A class-wide phylogenetic assessment of Dothideomycetes. Stud. Mycol. 2009, 64, 1-15. [CrossRef] [PubMed]

78. Ohm, R.A.; Feau, N.; Henrissat, B.; Schoch, C.L.; Horwitz, B.A.; Barry, K.W.; Condon, B.J.; Copeland, A.C.; Dhillon, B.; Glaser, F.; et al. Diverse lifestyles and strategies of plant pathogenesis encoded in the genomes of eighteen Dothideomycetes fungi. PLoS Pathog. 2012, 8, e1003037. [CrossRef] [PubMed]

79. Sachs, J.L.; Simms, E.L. Pathways to mutualism breakdown. Trends Ecol. Evol. 2006, 21, 585-592. [CrossRef]

80. Berg, G.; Rybakova, D.; Fischer, D.; Cernava, T.; Vergès, M.C.C.; Charles, T.; Chen, X.; Cocolin, L.; Eversole, K.; Corral, G.H.; et al. Microbiome definition re-visited: Old concepts and new challenges. Microbiome 2020, 8, 103. [CrossRef] [PubMed]

81. Tiago, P.V.; de Oliveira, N.T.; de Luna, E.Á.; Lima, A. Biological insect control using Metarhizium anisopliae: Morphological, molecular, and ecological aspects. Ciên. Rur. St. Maria 2014, 44, 645-651. [CrossRef]

82. Summerbell, R.C.; Gueidan, C.; Schroers, H.J.; de Hoog, G.S.; Starink, M.; Rosete, A.Y.; Guarro, J.; Scott, J.A. Acremonium phylogenetic overview and revision of Gliomastix, Sarocladium, and Trichothecium. Stud. Mycol. 2011, 68, 139-162. [CrossRef] [PubMed]

83. Summerell, B.A.; Laurence, M.H.; Liew, E.C.Y.; Leslie, J.F. Biogeography and phylogeography of Fusarium: A review. Fungal Divers 2010, 44, 3-13. [CrossRef]

84. Kaur, R.; Kaur, J.; Singh, R.S. Nonpathogenic Fusarium as a Biological Control Agent. Plant Pathol. J. 2010, 9, 79-91. [CrossRef]

85. Bilal, L.; Asaf, S.; Hamayun, M.; Gul, H.; Iqbal, A.; Ullah, I.; Lee, I.J.; Hussain, A. Plant growth promoting endophytic fungi Asprgillus fumigatus TS1 and Fusarium proliferatum BRL1 produce gibberellins and regulates plant endogenous hormones. Symbiosis 2018, 76, 117-127. [CrossRef] 